\title{
Impact of COVID-19 pandemic on the energy markets
}

\author{
Imlak Shaikh ${ }^{1}$
}

Received: 27 August 2020 / Accepted: 21 January 2021 / Published online: 17 February 2021

(c) The Author(s), under exclusive licence to Springer Science+Business Media, LLC part of Springer Nature 2021

\begin{abstract}
This article aims to uncover the effects of the COVID-19 pandemic on the energy markets in terms of energy stock indexes, energy futures, ETFs, and implied volatility indexes. We model the volatility of energy markets and demonstrate the effects of various phases of the pandemic outbreak (COVID-19) on the energy market. COVID-19-induced uncertainty indicators like the growth of the infection, economic policy uncertainty (EPU), and infectious diseases market volatility (IDsMV) have shown pronounced effects on energy markets' historical volatility. The volatility of energy ETFs-stocks appears to be more resilient in line with S\&P 500 energy stocks. WTI crude oil market has shown an unprecedented overreaction amid pandemic outbreaks and traded with an extreme volatility level. The investors' sentiment in the energy market was factually higher on the tail events, indicating that fearful investors rushed toward put options and paid an excess premium to protect from unparalleled risk in the energy market.
\end{abstract}

Keywords COVID-19 · Energy market · ETF · Pandemic · Volatility index · Uncertainty

JEL Classification B26 - G12 $\cdot \mathrm{G} 14 \cdot \mathrm{G} 15 \cdot \mathrm{Q} 02 \cdot \mathrm{Q} 43$

\section{Introduction}

The outbreak of the pandemic COVID-19 has rapidly disrupted the global supply chain and the economy; eventually, it has led to a dramatic transformation in the energy markets. Yet, it is unpredictable how long the virus outbreak will persist, which has shown its peak in the USA by mid of April 2020. The economic

Imlak Shaikh

imlak786@gmail.com; imlak.shaikh@mdi.ac.in

1 Management Development Institute Gurgaon, Gurugram, Haryana 122007, India 
normalcy exclusively depends on the immediate cure or vaccine or herd immunity increase. The analyst and policymakers believe that GDP may take a deep dive in 2020 and rebound in early 2021. ${ }^{1}$ The demand for energy and supply depends on the persistence of COVID-19 and further the lockdown, unlock and social distancing, and new workplace policy. Moreover, pandemic-induced unemployment is at the peak of about $10 \%$, and further, it may range between 15 and $30 \%$ (Figueroa et al. 2020). There have been large swings in the global crude oil prices, it dropped $50-80 \%$ in the first quarter of $2020^{2}$, and a $10 \%$ reduction in oil prices has caused approximately a $0.2 \%$ diminution in US GDP per year (Balke and Brown 2018). For the first time in the history of oil futures, WTI and Brent in near-term curves have fallen on average $20 \%$, and oil and gas companies face a growing risk of insolvency. Hence, in this work, we aim to present energy markets' performance amid COVID19 in terms of energy stocks, energy futures, energy EFTs, and energy market sentiment index (VIX). The work's motivation is to demonstrate how the energy market responds to the recent pandemic outbreak and find the effects of federal support and bailout package on the energy markets. The study's research questions are as follows: (1) What contains pandemic outbreak COVID-19 for the energy markets? (2) Does WHO announcements and federal support and bailout package matter for the energy trading? (3) Do OVX and OIV are the gauge of investor sentiment in the energy market?

IEA (2020) deliberates on the likely impact of COVID-19 and shows the concern about energy security, electricity security, and clean energy transitions in the year 2020. The report's key finding shows the unprecedented decline of global oil demand by minus $57 \%$ and a drop in road transport between 50 and $75 \%$. Cohen (2020) further refers to the IEA report (International Energy Agency) and highlights that it is the first time in the history of seven decades the biggest shock to the global energy market. Future shock implication is awaited. COVID-19 forced the companies, investors, and analysts to drill down to comprehend the tail events. The author notes that the energy market experienced a $6 \%$ decline in energy globally after the 2008 crisis. Developed economies are more vulnerable to face a fall of energy demand $9 \%$ in the USA and $11 \%$ across the EU. Moreover, Rapier (2020) analyzes the IEA outlook for the short-term energy market for 2020-2021. Brent crude oil may rise to $\$ 48 / \mathrm{b}$ in 2021 , global petroleum and liquid fuels demand may experience a considerable amount of volatility, and it may surge by 7.0 million b/d in 2021. Bocca (2020), a member of the World Economic Forum (WEF), explains the COVID-19 shocks to the global economy and energy market. The author considers it an opportunity for a new energy order in a sustainable fashion. COVID-19 crisis allowed more dialogue between the Organization of the Petroleum Exporting Countries (OPEC) and the G20. In order to deal with energy security and economic

\footnotetext{
1 Baker, S. R., Bloom, N., \& Terry, S. J. (2020c). Does Uncertainty Reduce Growth? Using Disasters as Natural Experiments. NBER, http://people.bu.edu/stephent/files/BBT.pdf.

2 Oil and Refined Products Summary, February 1, 2020, through April 3, 2020. S\&P Global Market Intelligence, Accessed June 3, 2020. https://platform.marketintelligence.spglobal.com/web/clien t?auth=inherit\#markets/OilSummary.
} 
uncertainty, several negotiations among OPEC + and the G20 are going on, and they are on the consensus to reduce the oil supply. Hence, COVID-19 allowed the ways of deployment of parties with contending interests to work toward the common and best objective of market's stability (e.g., AleaSoft 2020).

The historic decline in the demand for crude oil happened due to slower economic activity, international travel ban, lockdown, and geopolitics of crude oil among Saudi Arabia and Russia and OPEC's role in crude oil supply. Ramkumar and Hodari (2020) present the current and future crude scenario in the US Shale producers, Brent and WTI prices during the first quarter of 2020; crude oil futures first time fell below $\$ 20$. Wallace (2020) talks about crude backwardation and contagion effects, the rise in the futures prices near contract expiration. Before the pandemic outbreak, the SPXGSCI commodities index outperformed the SPX500, but commodities are still in contagion and backward state. The price of crude oil WTI to be delivered in May 2020, the first time in the history, traded at minus $\$ 5.33$ a barrel on April 21, 2020; the settlement price fell to minus $\$ 37.63$ (see Fig. 2); in particular, this implies that sellers must recompense buyers for taking barrels off their hands. ${ }^{3}$ Hence, our study contributes to several aspects: (1) energy market performance amid COVID-19 investigated in terms of energy stocks, futures, and ETF. (2) Further, energy traders' fear and anxiety were measured in terms of OVX and OIV amid pandemic and federal announcements.

Section 2 presents a review of earlier studies focused on various pandemics. Section 3 provides data description and preliminary analysis. Section 4 explains the empirical model and hypothesis development. Section 5 presents the results and discussion, and Sect. 6 reports a robustness check, and Sect. 7 ends with conclusion and policy implications.

\section{Literature review}

Laxminarayan and Malani (2006) present a review of the economics of infectious diseases across global economies. The primary observations of the economic literature on infectious diseases are that investment decisions and labor productivity remain the major consequences of the disorder's outbreak in many countries; further, it affects individual risk-taking behavior. The authors also report that to combat such infectious diseases, people assume more significant protective means to deal with unexpectedly high risk; for example, in our case, investors buy more and more put options to respond to such tail events. Suhrcke et al. (2011) performed a systematic literature survey concerning economic crises and infectious disease transmission. Many studies show worse effects of infectious disease following global financial crises materialized during 2007-2009. Furthermore, the authors also find a likelihood of an emergency's long-run impact on infectious

\footnotetext{
3 Caitlin Ostroff and Frances Yoon (2020) "U.S. Stocks Drop as Oil Market Shudders.

Dow falls more than 400 points; Brent crude drops to lowest level in 18 years" https:/www.wsj.com/ articles/global-stock-markets-dow-update-04-21-2020-11587443040.
} 
disease. Sands et al. (2016) provide a conceptual framework to factor economic vulnerability of contagious disease in macroeconomic forecasting and analysis. They insist on health authorities for providing digestible input data to perform economic forecasting. Hence, it is urgent to develop a new forecasting matrix that takes care of economic vulnerability to infectious disease crises.

Several studies (e.g., Kamstra et al. 2003; Kaplanski and Levy 2012; Cen and Yang 2013) find that sunshine, public holidays, and investors' anxiety and mood swings affect the returns and asset pricing. Moreover, another strand of studies (e.g., Yuen and Lee 2003; Kaplanski and Levy 2010; Donadelli et al. 2017) explains that unexpected and natural events impact investors' sentiments; subsequently, it affects the risk-taking behavior and fear for trading and lowers the willingness to participate in a risky investment. On the other hand, disease outbreaks show a positive effect on pharma stocks. Hence, our study extends the previous works on the relationship between energy stocks, energy futures, ETFs and investor sentiment, and COVID-19 DONs.

Chen et al. (2007) examine the effects of SARS in relation to the hospitability industry in Taiwan; in a window of SARS outbreak, tourism stock fell by $29 \%$. The authors analyze seven public companies in the hotel business and show that firms observed steep declines in the earnings and stock price crash during the SARS outbreak. Using an event study approach, they report significant adverse cumulative abnormal returns followed by the SARS event. Further, Chen et al. (2009) made an effort to study Taiwan's stock market concerning the SARS outbreak during 2003 using events study analysis and found that tourism and hospitality stock was negatively impacted, while the biotech sector experienced a positive shock of such diseases outbreak. Wang et al. (2013) also examined the effects of infectious disease outbreaks, for example, Enterovirus 71, dengue fever, SARS, and H1N1 on the biotech stocks in Taiwan. The authors explain that investors consider operational efficiency during the outbreaks of the above-mentioned infectious diseases and plan portfolios accordingly. More interestingly, Pendell and Cho (2013) uncover the effects of foot-and-mouth disease (FMD) on the Korean agribusiness stocks using the events study method and find an asymmetric stock market reaction to such FMD outbreak. Moreover, the authors report that a disease outbreak's effects are more gradual than instantaneous; companies in small size report considerable stock volatility than the other stocks.

Donadelli et al. (2017) studied the effects of disease-related news (DRNs) on the pharma stocks in the US setting. Administrations that wall street investors participate rationally in portfolio planning by taking the regard of the WHO media coverage. The authors find that DRNs hold encouraging and significant sentimental effects among investors and that effects are asymmetric between small and large companies. Unlike the work of Donadelli et al. (2017), our study employs an investor-sentiment-related index (OVX, VXXLE, and OIV) to uncover the effects of disease outbreak news (DONs) in the energy markets. We set our empirical hypothesis that "DONs impact investor sentiment adversely," and it is measured in terms of the OVX, also known as investors' fear index (Whaley 2000). We present the taxonomy of the consequences of a past pandemic outbreak on various markets in Table 1. 


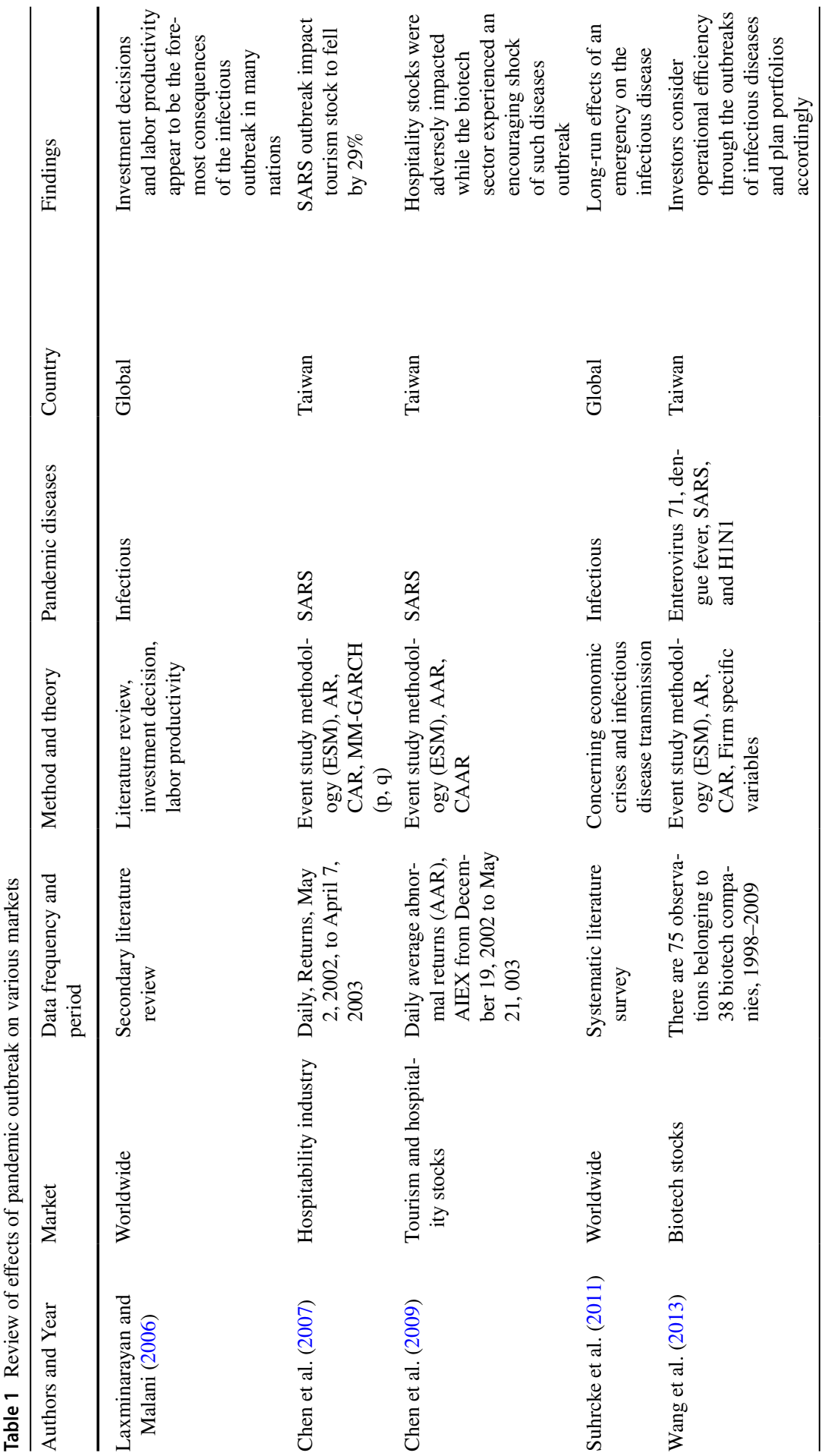




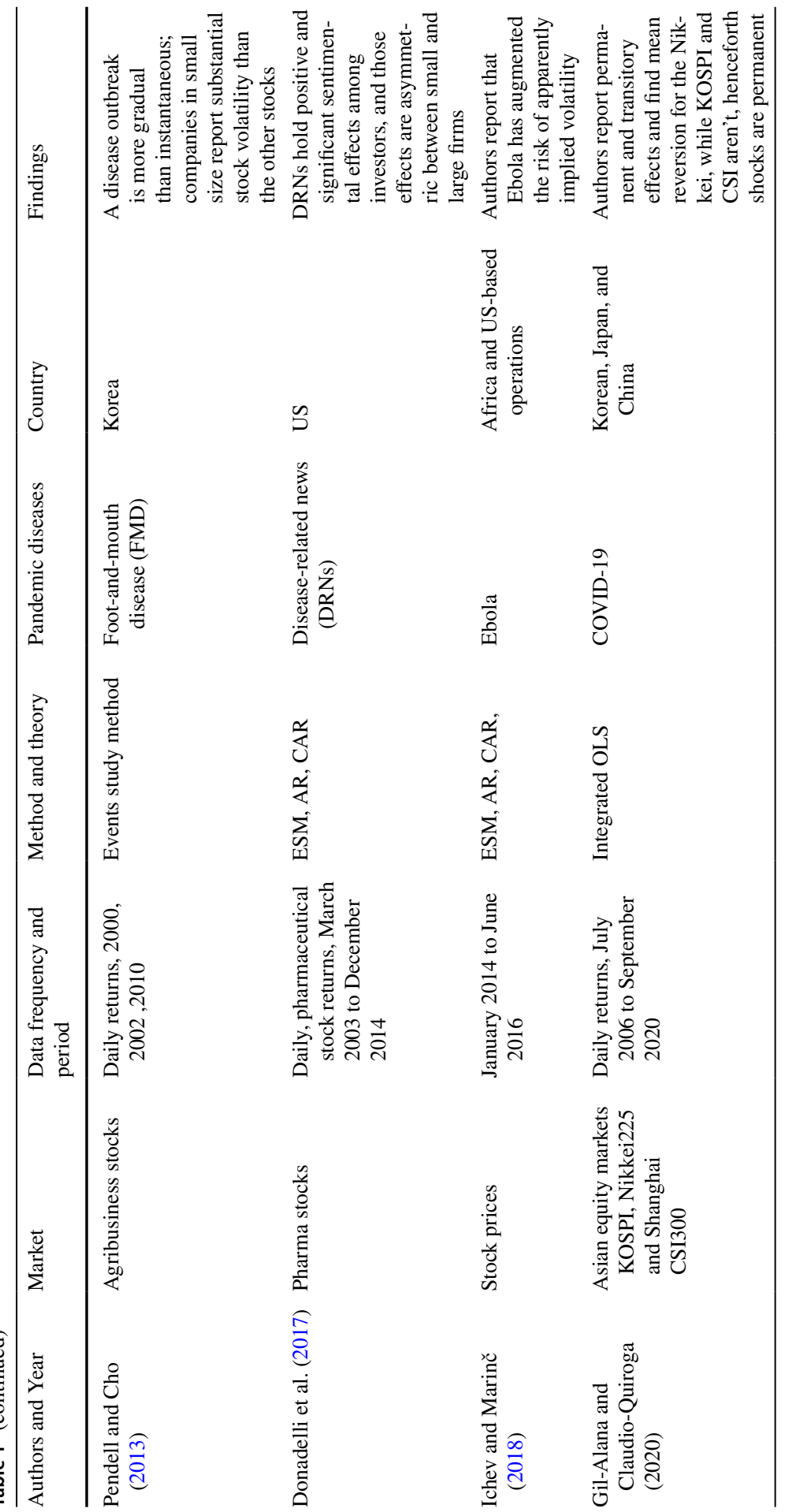




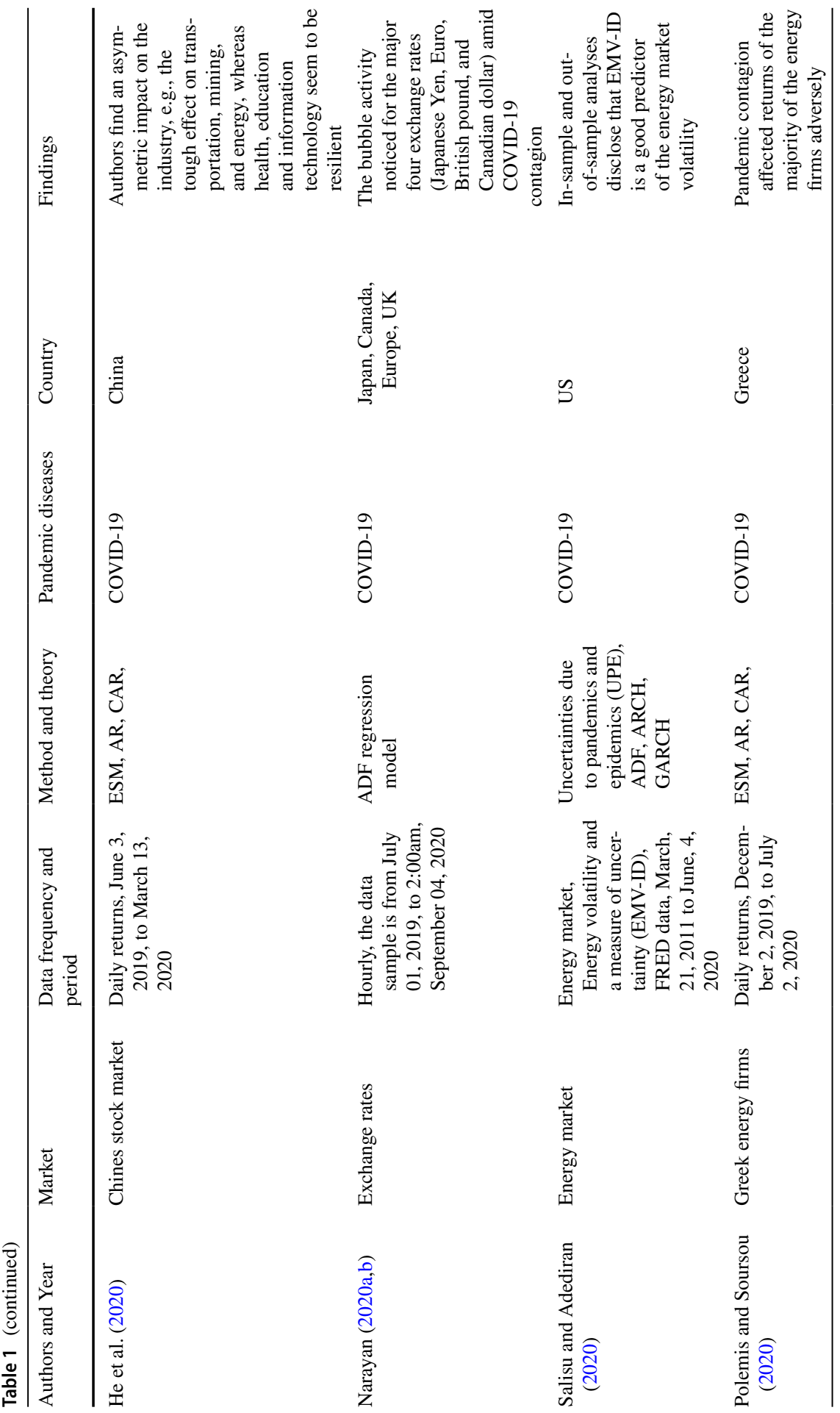




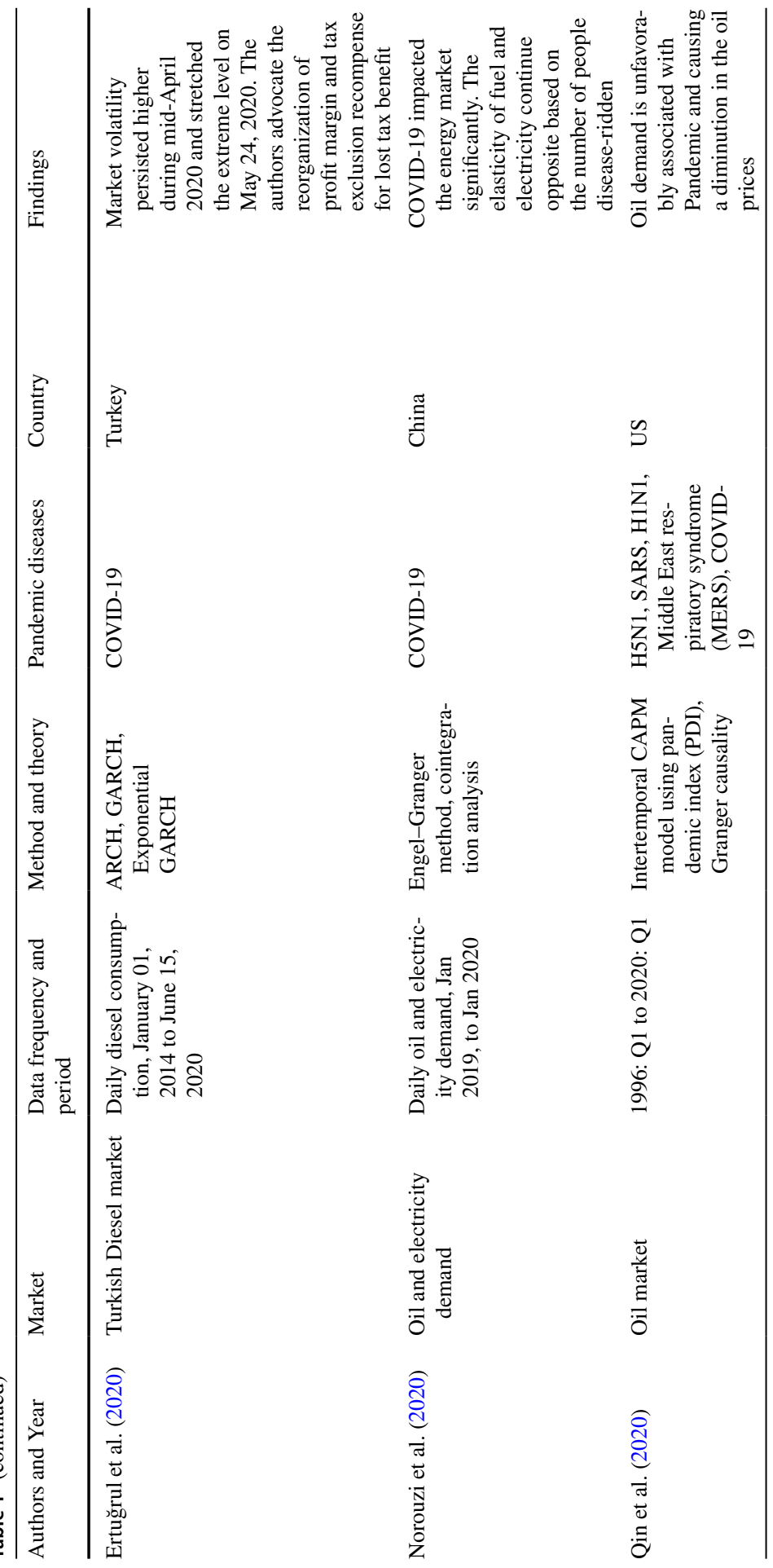




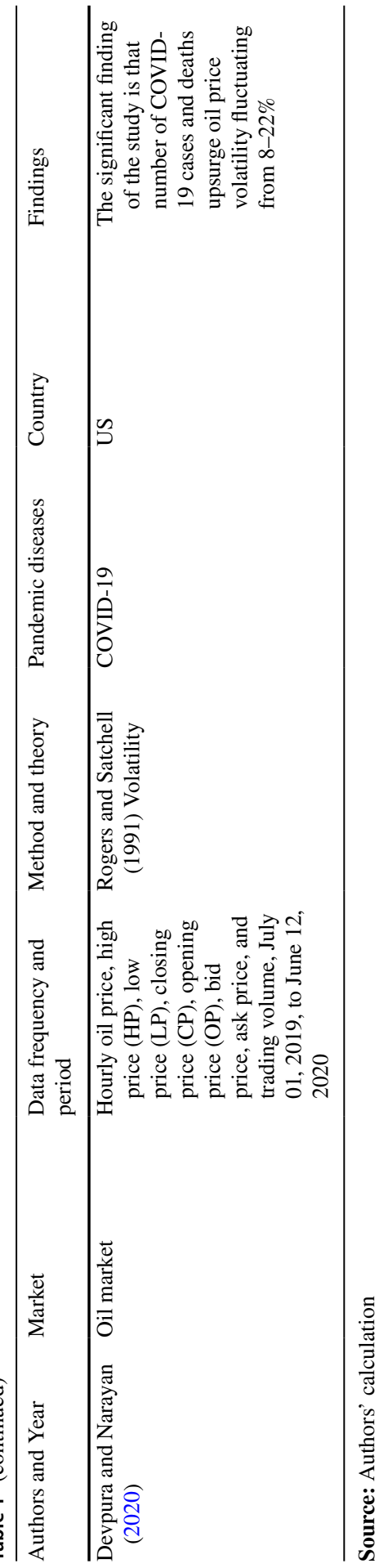


Ichev and Marinč (2018) examine the effects of the Ebola outbreak event for the period 2014-2016 on the stock prices in the context of geographic proximity information and find a substantial impact on the stock linked with the geographical location like those situated in West Africa and US-based operations. Authors reveal that the epicenter of the pandemic outbreak event holds a significant role in explaining the financial markets' functioning, and effects are more pronounced in stock of smaller firms, industry-specific stock, and stocks with media exposure. Authors also report that Ebola has increased the risk of perceived implied volatility.

There has been some recent descriptive documentations on the effects of the COVID-19 outbreak on the US economy. Baker et al. (2020a) employ a text-based quantitative framework to bring insights into the recent COVID-19 outbreak in the US equity market. The text-based archival analysis shows that recent stock market volatility has surpassed the ex post volatility level of October 1987, GFC-2008, and the period great recession 1929-1930. Authors have presented excellent work on infectious disease outbreaks such as COVID-19 development and COVID-19-induced uncertainty. In the past, on the comparative analysis of several pandemic developments, none of the pandemic events has affected the stock market's performance as significantly as COVID-19. Likewise, Baker et al. (2020b) present one more piece of work on COVID-19-induced economic uncertainty. As the question has been raised by Sands et al. (2016) about economic forecasting induced by an infectious disease outbreak, Baker et al. (2020c, henceforth BBT) took this opportunity to build text-based forward-looking measures of economic uncertainty caused by COVID-19. BBT forecast the US real GDP using uncertainty shock and find contraction of output about $11 \%$ as of Q4-2020, which implies that COVID-19 persuades adverse effects. Hence, in our empirical model, we add COVID-19-induced economic uncertainty as one of the factors to explain the energy markets and future level of implied volatility.

Corbet et al. (2020) examine reputation-based contagion during the COVID19 outbreak choosing stocks of the firms labeled with corona. Authors find that COVID-19-induced risk is more pronounced for companies related to the term corona, and there is an existence of sharp, dynamic, and more connections among those firms. Further, Kanno (2020) analyzes the contagion risk of COVID-19 on the Japanese stock market using network theory and interconnectedness between pandemic infection and financial network. Akhtaruzzaman et al. (2020) study the financial contagion amid the COVID-19 crisis among China and G7 nations. Authors administer the empirical work on the financial and non-financial firms and find that conditional correlations remain higher for the financial firms during the pandemic outbreak and higher hedging ratios and cost.

Zaremba et al. (2020) analyze government intervention's effects amid COVID-19 on the global equity market and find that non-pharmaceutical intervention significantly increases stock volatility. Baig et al. (2020) investigate the US equity markets in relation to the growth of the COVID-19 cases using the pandemic index and find that daily confirmed cases of infection and death caused a significant increase in market volatility and illiquidity. Moreover, Ashraf (2020) examine the equity market reaction to COVID-19 fatalities across 64 countries and find stock market reactions remain more proactive to the growth in the number of infection cases than the 
number of deaths. Further, Smales (2020) studies the investors' attention and global equity market amid the COVID-19 crisis using Google Search Volume (GSV), economic policy uncertainty (EPU), and lagged returns in the empirical model and find that GSV-based investor attention explains global stock returns adversely.

Ozili (2020) surveys the likely impact of COVID-19 on the African continent in socioeconomic impact, policy uncertainty response, and opportunities. The bold decisions during the pandemic have impacted the health systems and economic crisis in African countries. The author advises more public funds, liquidity, and labor layoff support to respond to future challenges. Ji et al. (2020) study the pandemic uncertainty and search for the safe-haven assets class, namely cryptocurrency, commodities, FX, and gold, and find that in the pre-pandemic period, all these assets are less effective but during the pandemic period, gold and soybean act as safe-haven. Moreover, Demir et al. (2020) examine the infection of COVID-19 on the cryptocurrencies market based on infection cases and deaths and find a negative relation during the pandemic and later a supportive relationship.

Papadamou et al. (2020) investigate the major implied volatility indexes and google synthetic trend index amid coronavirus outbreak and find that google-based panic about pandemic infection results in contagion effects and leads to risk aversion in the global equity markets. Seven and Yilmaz (2020) also deliberate on the recovery and response prospects of the world equity markets amid COVID-19 and attempt to see the impact of rescue packages in terms of size and type. Authors find overreaction of the equity market with higher COVID-19-related cases and death and also report that all kinds of put protections are not equally effective.

More recently, Al-Awadhi et al. (2020) investigated the impact of COVID-19 on the Chinese stock market using panel data regression. The authors in their research show that death and contagious infectious diseases impact the Chinese equity market and reveal that daily new cases and the total number of deaths due to the illnesses exhibited adverse stock returns. The work of Al-Awadhi et al. (2020) and the research agenda set by Goodell (2020) demonstrate the fatal and contagious effects of COVID-19 across global equity markets. Moreover, Bakas and Triantafyllou (2020) studied commodity price and pandemic uncertainty and found a substantial adverse impact on the commodity market and was more pronounced in the crude oil market. Ali et al. (2020) examine the COVID-19 global financial market's impact and report that the Chinese market remains more stable after the outbreak. Still, the global financial system has disrupted due to a Coronavirus outbreak across other countries, mainly followed by Europe and the USA. Haroon and Rizvi (2020) further deliberate on the relation between COVID-19 Media coverage and financial market reactions and find overwhelming panic produced by the news media coverage and increased volatility in the equity markets. Further, Zhang et al. (2020) analyze the rapid growth of COVID-19 across the globe and its impact on the financial market; authors find that zero percent interest rate and unrestricted quantitative easing (QE) can help to recover the recent loss in the financial markets.

More specifically, current studies concerning COVID-19 and energy market (Narayan 2020a, b, c; Gil-Alana and Monge 2020; Liu et al. 2020; Apergis and Apergis 2020) examine, for example, COVID-19 infections and oil price news and political polarization, pandemic and volatility persistence and find that 
pandemic outbreak has disrupted the global crude oil prices and escalated in increased volatility and oil price conflicts. Some of the most prominent studies in relation to public health crises and market reactions (e.g., Schell et al. 2020; Huynh et al. 2020; Goodell and Huynh 2020; Pham and Huynh 2020) established a relation that energy market risk remains higher amid unprecedented event like pandemic COVID-19. Hence, unlike the previous studies, our study contributes in terms of energy stock indexes, crude oil futures, energy ETFs, and investors' sentiment in the energy trading amid COVID-19 infectious diseases outbreak.

\section{Data description and preliminary analysis}

\subsection{Data sources and description}

The pandemic COVID-19 has bent the major global crisis in generations, transfer shock waves over health systems, economies, and societies around the world. The energy market has shown an unprecedented overreaction. Administrations are engrossed in bringing the disease under control and stimulating their economies. The disruption of economic activity has led to a decline in demand for energy between 18 and 25\%. Consequently, it resulted in a higher risk premium and lower returns in the energy markets. Our empirical work demonstrates returns and volatility relations amid COVID-19 in the energy markets, presenting a comprehensive analysis concerning energy stocks index, futures contract, energy ETFs, and energy ex ante volatility indexes. Our empirical study in relation to a pandemic is based on the daily prices of the energy market; the sample period ranges from January 1, 2011, to May 31, 2020 (Martín-Oliver and Silaghi 2020; Ichev and Marinč 2018). The energy market-linked stock indexes are Dow Jones US Oil and Gas Index (DJUSEN), S\&P 500 Energy Index (SPN), and Dow Jones Commodity Index (DJCI). DJUSEN index measures the performance of oil and gas companies in the USA. SPN, another energy sector index, consists of firms encompassed in the S\&P 500 designated as the GICS $®$ energy market members. In our market model, we need a broad market benchmark index; we employ DJCI, an overall measure of the commodity futures market that stresses divergence and liquidity based on the equally weighted schemes. Besides, we consider the daily price of Crude Oil WTI Futures and Brent Crude Oil Futures for the stated sample. Further, our study attempts to analyze energy ETFs' performance such as iShares US Energy ETF, ProShares Short, and Gas ETF, ProShares Ultra Oil, and Gas ETF ProShares Ultra Oil and Gas ETF (see "Appendix A"). Our study also examines the investors' fear in the energy market gauged in terms of OVX, VXXLE, and OIV volatility indexes (see "Appendix B"). Our empirical model employs various pandemic-related events and announcements such as a weekly measure to combat COVID-19, Federal actions, FOMC minutes, WHOs reports, and Unemployment and GDP data releases (see "Appendix C"). 


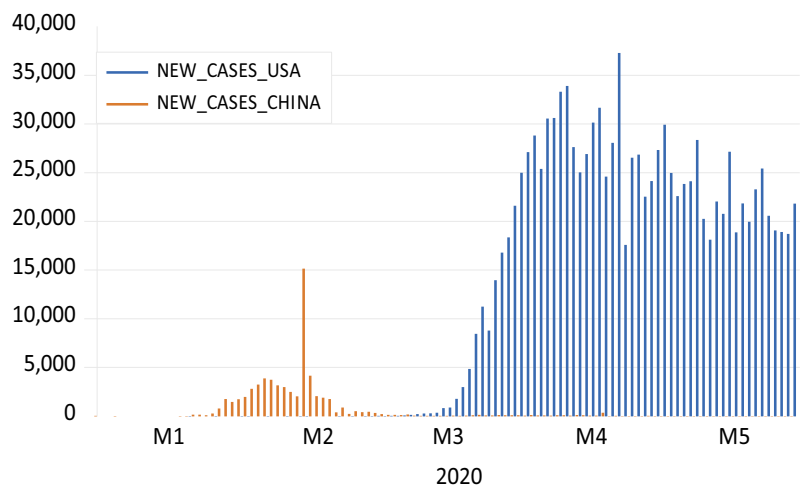

Fig. 1 COVID-19 outbreak cases in China and USA, December 29, 2019, to May 31, 2020

\subsection{Descriptive statistics and preliminary analysis}

Figure 1 displays the plot of COVID-19 growth cases in China and the USA. The chart shows daily and total COVID-19 cases in China and the USA; it is apparent that daily new China cases were increasing during February 2020. The USA started takeoff from March 2020 and grew exponentially through March-April and marginally declining in May 2020. The increased cases of COVID-19 have disrupted the global supply chain and financial system; lockdown and suspension of international travel have resulted in decreased consumption of fuel and, consequently, lack of demand for crude oil. The oversupply of crude, storage issue, and OPEC negotiations have raised uncertainty in the energy market, and still, WTI and Brent are struggling to find the best price of global crude oil.

Table 2 displays the summary statistics in relation to energy market indexes, commodity index, and equity market indexes. Panel A exhibits descriptive measures for the full sample, and Panel B shows for the pandemic outbreak period (DONs, disease outbreak news). First, we compare the average returns among all markets. We can see that energy and commodity markets experienced negative returns, while the equity market segment has yielded positive returns. Albeit, during the pandemic session, both markets have observed negative returns, but energy markets reported the highest adverse return. Looking at the maximum and minimum level of the indexes during the pandemic crisis, the low level of DJSEN found to be 193.83, and the peak was 505.18, with an average reading of 352.96 . We find similar patterns for other commodity and equity indexes. There has been a vast difference between max and min values, indicating an unprecedented impact of COVID-19. The dispersion measure shows that energy and commodity experienced an enormous amount of volatility compared to equity markets. Further, indicators of normality also appear to be non-normal.

Table 3 describes the Futures market of WTI and Brent Crude oil. One can see that during the pandemic, WTI traded minus 37.63 with an average level of 36.92 . At the same time, Brent was at a minimum of 19.33 with a mean level of 42.50 . One can see that Brent yields better returns than the WTI during the pandemic period, 


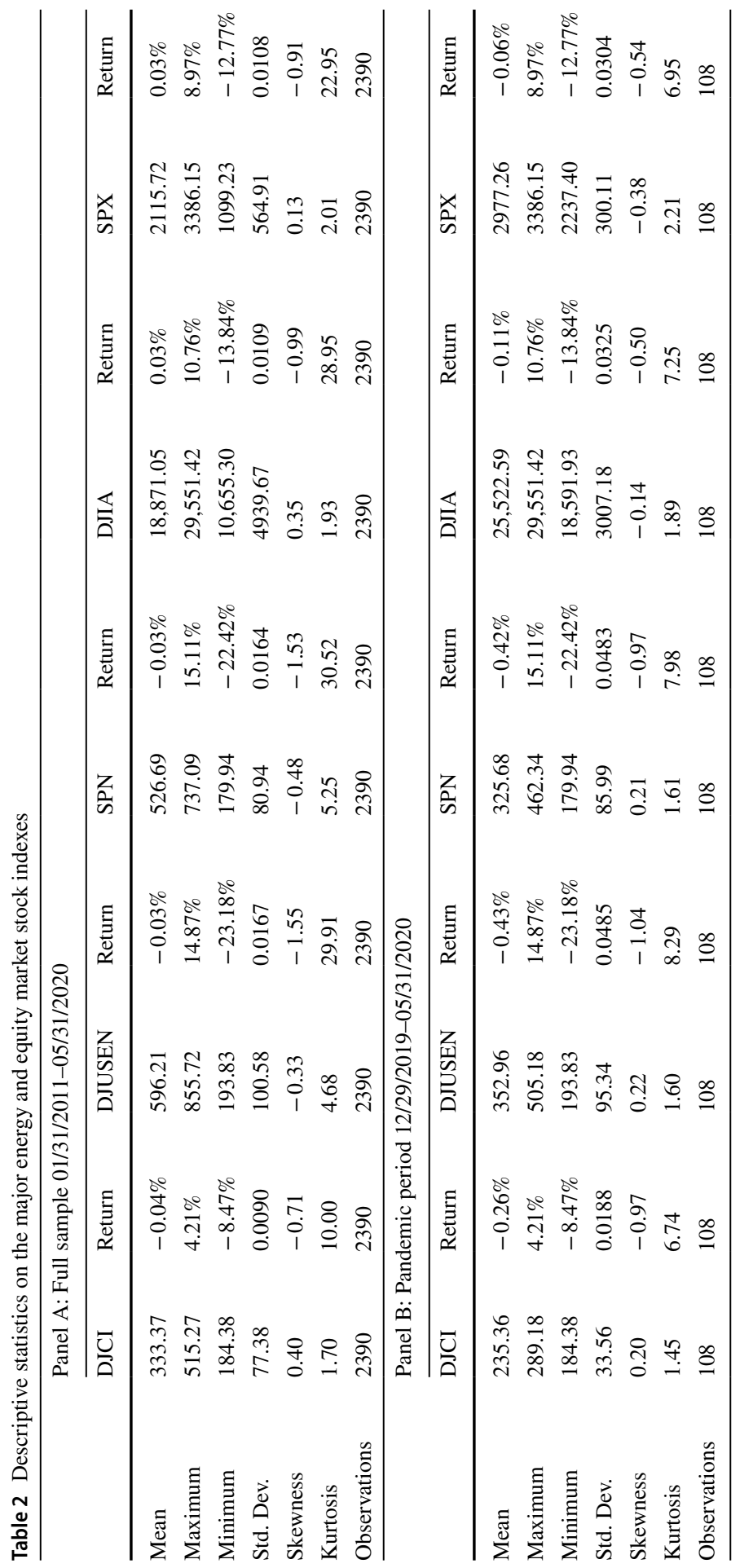


Table 3 Descriptive statistics on the global crude oil futures

\begin{tabular}{lllll}
\hline & \multicolumn{4}{l}{ Panel A: Full sample 01/31/2011-05/31/2020 } \\
\cline { 2 - 5 } & WTI & Return & BRENT & Return \\
\hline Mean & 69.49 & $-0.03 \%$ & 77.60 & $-0.05 \%$ \\
Maximum & 113.93 & $31.96 \%$ & 126.65 & $19.08 \%$ \\
Minimum & -37.63 & $-28.22 \%$ & 19.33 & $-27.98 \%$ \\
Std. Dev. & 23.70 & 0.0271 & 27.70 & 0.0231 \\
Skewness & 0.10 & 0.30 & 0.15 & -1.05 \\
Kurtosis & 1.87 & 34.16 & 1.58 & 26.07 \\
Observations & 2390 & 2390 & 2390 & 2390 \\
\hline & Panel B: Pandemic period 12/29/2019-05/31/2020 & \\
\cline { 2 - 5 } & WTI & Return & BRENT & Return \\
\hline Mean & 36.92 & $-0.04 \%$ & 42.50 & $-0.58 \%$ \\
Maximum & 63.27 & $31.96 \%$ & 68.91 & $19.08 \%$ \\
Minimum & -37.63 & $-28.22 \%$ & 19.33 & $-27.98 \%$ \\
Std. Dev. & 17.06 & 0.0857 & 15.62 & 0.0629 \\
Skewness & -0.62 & 0.20 & 0.23 & -1.02 \\
Kurtosis & 4.50 & 7.24 & 1.48 & 8.97 \\
Observations & 108 & 108 & 108 & 108 \\
\hline
\end{tabular}

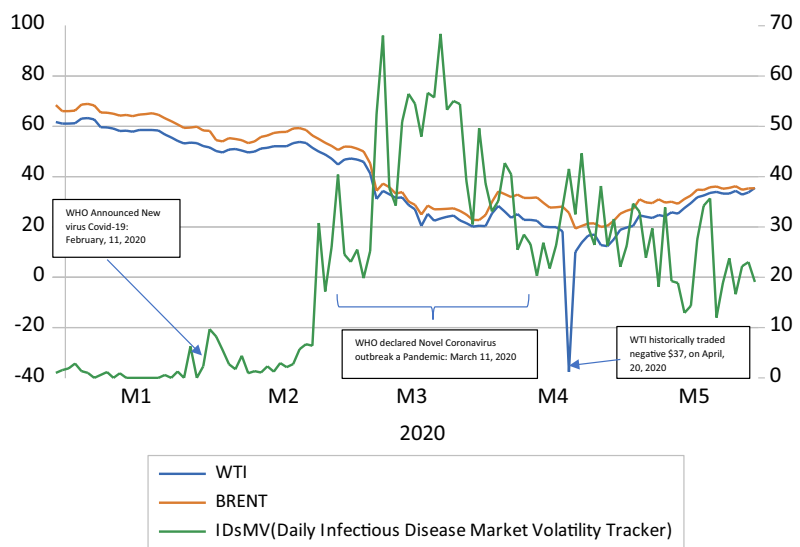

Fig. 2 Pandemic infection in the crude oil futures market

and further WTI appears to be more volatile than the Brent. Figure 2 visualizes WTI and Brent's co-movement following the market infection, and it is visible that IDsMV tracker reaches its peak during March 2020 and crude oil futures traded historically low. And during the second phase of the pandemic outbreak, during the April WTI first time in history traded negatively. 
Table 4 Descriptive statistics of the important ETFs available for the energy stocks

\begin{tabular}{|c|c|c|c|c|c|c|c|c|}
\hline & \multicolumn{8}{|c|}{ Panel A: Full sample 01/31/2011-05/31/2020 } \\
\hline & IYEETF & Return & DDGETF & Return & DIGETF & Return & DUGETF & Return \\
\hline Mean & 39.95 & $-0.03 \%$ & 27.65 & $-0.01 \%$ & 433.22 & $-0.09 \%$ & 59.95 & $-0.04 \%$ \\
\hline Maximum & 57.72 & $14.92 \%$ & 54.60 & $18.46 \%$ & 906.10 & $27.42 \%$ & 169.15 & $35.15 \%$ \\
\hline Minimum & 12.58 & $-23.14 \%$ & 20.67 & $-17.83 \%$ & 33.60 & $-47.73 \%$ & 28.25 & $-38.76 \%$ \\
\hline Std. Dev. & 6.90 & 0.0167 & 4.79 & 0.0173 & 158.04 & 0.0325 & 25.85 & 0.0325 \\
\hline Skewness & -0.38 & -1.51 & 1.15 & 0.43 & 0.47 & -1.73 & 1.35 & -0.19 \\
\hline Kurtosis & 4.73 & 29.44 & 4.58 & 19.27 & 3.46 & 30.56 & 4.27 & 23.06 \\
\hline \multirow[t]{3}{*}{ Observations } & 2390 & 2390 & 2390 & 2390 & 2390 & 2390 & 2390 & 2390 \\
\hline & \multicolumn{8}{|c|}{ Panel B: Pandemic period 12/29/2019-05/31/2020 } \\
\hline & IYEETF & Return & DDGETF & Return & DIGETF & Return & DUGETF & Return \\
\hline Mean & 22.78 & $-0.42 \%$ & 32.73 & $0.18 \%$ & 129.22 & $-1.07 \%$ & 63.48 & $0.14 \%$ \\
\hline Maximum & 32.54 & $14.92 \%$ & 54.60 & $18.46 \%$ & 262.80 & $27.42 \%$ & 169.15 & $35.15 \%$ \\
\hline Minimum & 12.58 & $-23.14 \%$ & 24.22 & $-17.83 \%$ & 33.60 & $-47.73 \%$ & 37.24 & $-38.76 \%$ \\
\hline Std. Dev. & 6.17 & 0.0481 & 7.33 & 0.0460 & 78.23 & 0.0916 & 29.08 & 0.0928 \\
\hline Skewness & 0.21 & -1.05 & 1.10 & 0.14 & 0.44 & -1.20 & 1.75 & -0.26 \\
\hline Kurtosis & 1.57 & 8.50 & 3.62 & 6.98 & 1.52 & 9.39 & 5.66 & 7.07 \\
\hline Observations & 108 & 108 & 108 & 108 & 108 & 108 & 108 & 108 \\
\hline
\end{tabular}

Table 4 exhibits the market performance of exchange-traded funds (ETFs) available on most actively traded energy stocks. One of the essential observations from the descriptive statistics is that all ETFs have reported negative returns when looking at the sample as a whole while seeing the pandemic outbreak period DDG-ETF $(0.18 \%)$ and DIG-ETF $(0.14 \%)$ revert with the positive returns. It implies that energy EFTs better track the energy markets' performance and yield better returns following tail events. Also, one can notice that during the COVID-19 infection period, iShares and ProShares Ultra Oil and Gas ETFs appear to be negative and are in line with the returns of DJUSEN and SPN. The detailed analysis insights that ProShares Short Oil and Gas and ProShares UltraShort Oil and Gas ETFs are more defensive following the tail events.

Table 5 shows a summary of the important energy markets' volatility indexes. VIX is the official trademark of the CBOE. The CBOE has licensed the product to other exchanges to calculate volatility indexes that varied financial assets and the energy market as well. VIX index is the forecast of the future expected volatility, which is to be realized in the next 20-22 trading days. The implied volatility index is an ex ante measure of the investors' fear and anxiety, which is observed in the traded call or put option prices. OVX is one of the most preferred readings of the investors' sentiment in the energy market. During the pandemic, the average reading was $89.88 \%$, with a maximum of $325.15 \%$ and a minimum of $27.66 \%$. Similarly, VXXLE, a volatility index of the energy sector, seems to be, on average, 51.62\%, Max. (130.61\%) and Min. (15.10\%). Looking at these numbers, 
Table 5 Descriptive statistics on the energy markets' investors' sentiment indexes

\begin{tabular}{llll}
\hline & \multicolumn{2}{l}{ Panel A: Full sample 01/31/2011-05/31/2020 } & OIV \\
\cline { 2 - 4 } & OVX & VXXLE & 40.52 \\
Mean & 35.73 & 24.06 & 1418.47 \\
Maximum & 325.15 & 130.61 & 13.47 \\
Minimum & 14.50 & 11.71 & 67.24 \\
Std. Dev. & 20.27 & 11.11 & 11.61 \\
Skewness & 5.25 & 4.00 & 163.57 \\
Kurtosis & 45.95 & 26.65 & 2391 \\
Observations & 2391 & 2391 & \\
\hline & Panel B: Pandemic period & $12 / 29 / 2019-05 / 31 / 2020$ & OIV \\
\cline { 2 - 4 } & OVX & VXXLE & 204.95 \\
& 89.88 & 51.62 & 1418.47 \\
Mean & 325.15 & 130.61 & 27.43 \\
Maximum & 27.66 & 15.10 & 264.37 \\
Minimum & 60.15 & 30.72 & 2.17 \\
Std. Dev. & 1.04 & 0.58 & 7.51 \\
Skewness & 3.93 & 2.41 & 108 \\
Kurtosis & 108 & 108 & \\
Observations & &
\end{tabular}

Table 6 Correlation coefficient matrix

\begin{tabular}{|c|c|c|c|c|c|c|c|c|}
\hline \multirow[b]{2}{*}{$\begin{array}{l}\text { Energy mar- } \\
\text { kets indicators }\end{array}$} & \multicolumn{4}{|c|}{ Full sample } & \multicolumn{4}{|c|}{ Sub-sample (DONs) } \\
\hline & EPU & $p$ value & IDsMV & $p$ value & EPU & $p$ value & IDsMV & $p$ value \\
\hline DJCI & 0.0273 & 0.183 & -0.2575 & $0.000 *$ & -0.9075 & $0.000 *$ & -0.7197 & $0.000 *$ \\
\hline DJUSEN & -0.4175 & $0.000 *$ & -0.5087 & $0.000^{*}$ & -0.8490 & $0.000 *$ & -0.8837 & $0.000 *$ \\
\hline SPN & -0.4438 & $0.000 *$ & -0.5334 & $0.000 *$ & -0.8481 & $0.000 *$ & -0.8845 & $0.000 *$ \\
\hline WTI & -0.0732 & $0.000^{*}$ & -0.3064 & $0.000 *$ & -0.8685 & $0.000 *$ & -0.7292 & $0.000 *$ \\
\hline BRENT & -0.0024 & 0.907 & -0.2798 & $0.000 *$ & -0.8973 & $0.000 *$ & -0.7905 & $0.000^{*}$ \\
\hline IYEETF & -0.4206 & $0.000 *$ & -0.5137 & $0.000 *$ & -0.8553 & $0.000 *$ & -0.8814 & $0.000^{*}$ \\
\hline DDGETF & 0.4648 & $0.000 *$ & 0.3527 & $0.000 *$ & 0.6083 & $0.000 *$ & 0.8811 & $0.000^{*}$ \\
\hline DIFETF & -0.3053 & $0.000 *$ & -0.3705 & $0.000 *$ & -0.8706 & $0.000 *$ & -0.8453 & $0.000 *$ \\
\hline DUGETF & 0.3292 & $0.000 *$ & 0.1398 & $0.000 *$ & 0.4297 & $0.000 *$ & 0.8027 & $0.000 *$ \\
\hline ovX & 0.5754 & $0.000 *$ & 0.7492 & $0.000 *$ & 0.8024 & $0.000^{*}$ & 0.7509 & $0.000 *$ \\
\hline VXXLE & 0.5765 & $0.000 *$ & 0.7584 & $0.000 *$ & 0.7182 & $0.000 *$ & 0.9096 & $0.000 *$ \\
\hline OIV & 0.5466 & $0.000 *$ & 0.5807 & $0.000 *$ & 0.6146 & $0.000 *$ & 0.3341 & $0.000 *$ \\
\hline
\end{tabular}

Significant at $* 1 \%, * * 5 \%, * * * 10 \%$ level 

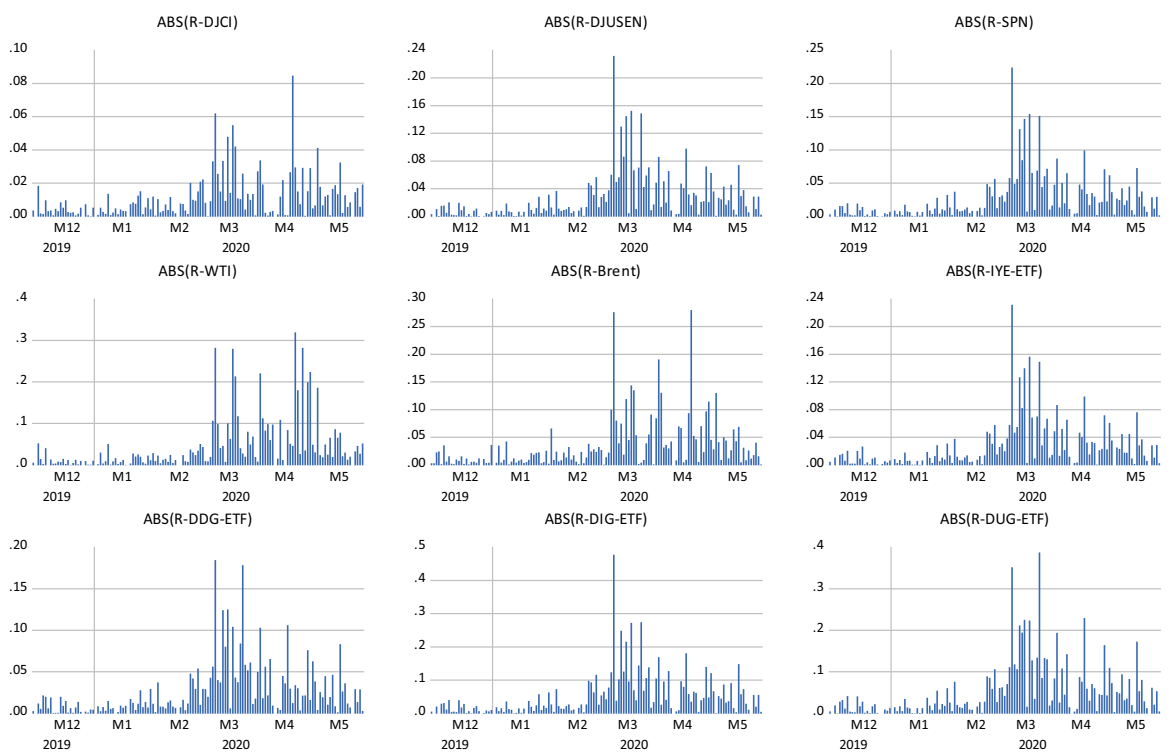

Fig. 3 Energy markets volatility—absolute returns

one can infer that pandemic has caused a significant amount of panic and fear among the energy investors and an excessive burden on the energy options that resulted in the increased amount of risk premium. On the other hand, OIV is NYMEX WTI Futures-based implied volatility index, and the average OIV measured $40.52 \%$ (full sample) and $204.95 \%$ (pandemic period). It means that there is a lack of hedge funds to manage crude oil risk; overburden on the crude oil options results in large fluctuations of options price, consequently higher level of expected energy market volatility.

Table 6 demonstrates the correlation coefficient between energy markets and economic and pandemic uncertainty. By convention, assets' price and uncertainty are negatively associated, and market volatility should rise when uncertainty increases. We can see that the energy market and uncertainty market indicators (economic policy uncertainty and infectious diseases market volatility) exhibit significant adverse associations (full sample) and appear about twice during the pandemic outbreak period. The WTI and Brent also responded negatively during the disease outbreak news period. One of the essential observations is that ETFs, namely DDG and DUG, remain insensitive to COVID-19 infection and economic uncertainty. The energy market uncertainty (OVX-VXXLE-OIV) and pandemic outbreak show a significant positive association. The degree of association is more pronounced during the DONs period. One can see that the coefficient of correlation between VXXLE and IDsMV stood at 0.91. Figure 3 shows the energy market volatility expressed as absolute values of returns calculated for the energy indexes. We can see that energy market volatility is more pronounced following the pandemic session from February-April 2020 and then decline exponentially. 


\section{Empirical model and hypothesis development}

The relation between COVID-19 and the energy market crisis is presented threefold: an unconditional analysis, a conditional volatility framework, and an investors' sentiment model.

\subsection{Unconditional model}

We employ an extended market model to probe into the risk-return trade-off amid COVID-19 in the energy markets (e.g., Lean and Nguyen 2014; Martín-Oliver and Silaghi 2020). We consider multiple numbers of dummies in our excess return market model and denoted with $D_{t}$. $D_{t}$ assumes one for the COVID-19 development otherwise zero-such as weekly disease outbreaks news, WHO announcement, FOMC, and Federal announcements. The excess returns market model,

$$
\begin{gathered}
\left(R_{i, t}-R_{f}\right)=\alpha_{0}+\alpha_{1}\left(R_{m, t}-R_{f}\right)+e_{t} \\
\left(R_{i, t}-R_{f}\right)=\alpha_{0}+\alpha_{1}\left(R_{m, t}-R_{f}\right)+\alpha_{2} D_{i, t}+e_{t}^{\prime} .
\end{gathered}
$$

Equation (1-2) is the baseline model, and we further modify the model by taking into account economic policy uncertainty (EPU) and infectious disease market volatility tracker (IDsMV). The augmented regression specification is expressed as

$$
\begin{aligned}
\left(R_{i, t}-R_{f}\right)= & \beta_{0}+\beta_{1}\left(R_{m, t}-R_{f}\right)+\beta_{2} \Delta \ln (E P U)_{t-1} \\
+ & D_{i, t}\left\{\pi_{0}+\pi_{1}\left(R_{m, t}-R_{f}\right)+\pi_{2} \Delta \ln (E P U)_{t-1}\right\}+u_{t} \\
\left(R_{i, t}-R_{f}\right)= & \Upsilon_{0}+\Upsilon_{1}\left(R_{m, t}-R_{f}\right)+\Upsilon_{2} \Delta \ln (I D s M V)_{t-1} \\
& +D_{i, t}\left\{\mu_{0}+\mu_{1}\left(R_{m, t}-R_{f}\right)+\mu_{2} \Delta \ln (I D s M V)_{t-1}\right\}+u_{t} \\
\left(R_{i, t}-\right. & \left.R_{f}\right)=\alpha_{0}+\alpha_{1}\left(R_{m, t}-R_{f}\right)+\alpha_{j 2} D_{j i, t}+e_{t}^{\prime}
\end{aligned}
$$

where $R_{i, t}=$ log-transformed contemporaneous returns on the energy sector indexes (Dow Jones US Oil and Gas Index, S\&P500 Energy Index, WTI Futures, Brent Futures, iShares US Energy ETF, Pro-Shares Short Oil and Gas ETF, ProShares Ultra Oil \& Gas, Pro-Shares Ultra-Short Oil and Gas). $R_{m, t}=$ log-transformed contemporaneous returns on the benchmark commodity index (e.g., Dow Jones Commodity Index). $R_{f}=$ the risk-free rate proxied from US treasury bill rates. $\Delta \ln (E P U)_{t-1}=$ the change in the economic policy uncertainty with one period lag. $\Delta \ln (I D s M V)_{t-1}=$ a change in the infectious diseases market volatility tracker with one period lag (Baker et al. 2020a). $D_{i, t}=$ disease outbreak new period. $D_{j i, t}=$ the COVID-19 development phases during weeks or months. Further, it measures the period for major Federal decisions (Zaremba et al. 2020), e.g., FOMC statement days, bailout package, quantitative easing. Our empirical hypothesis stands, "Energy 
market excess returns and COVID-19 are adversely associated," while "Energy markets' returns and Federal announcement are positively associated."

\subsection{Conditional model}

We further present our COVID-19-induced conditional volatility framework using the GJR-GARCH model. Market volatility is recognized in terms of volatility clustering. A volatile period tends to persist due to the pandemic news (DONs) outbreak before the market proceeds to normalcy. Most widespread studies show that historical volatility models forecast better than ARCH and stochastic volatility models (e.g., Taylor 1987; Figlewski 1997; Green and Figlewski 1999; Andersen et al. 2001; and Taylor 2004). ARCH models do not use the past standard deviations but formulate conditional variance with maximum likelihood procedure. GARCH model (Benzid and Chebb 2020) that also allows for asymmetrical dependencies includes the GJR-GARCH proposed by Glosten et al. (1993) and application of GJR-GARCH model in the ASEAN (Association of Southeast Asian Nations) market well documented by Nguyen and Huynh (2019) and Duong and Huynh (2020). In order to regard information of asymmetry of the DONs, we model the energy market volatility using the GJR-GARCH $(1,1)$ model as follows:

Let, $R_{i, t}$ be the log-transformed returns on the ith energy markets indexes,

$$
\begin{gathered}
R_{i, t}=\mu+\in_{t} \\
\epsilon_{t}=\sqrt{h_{t} z_{t}} \\
h t=\omega+\sum_{i=1}^{p} \beta_{i} h_{t-i}+\sum_{j=1}^{q}\left(\alpha_{j} \in_{t-j}^{2}+\delta_{j} D_{j, t-1} \in_{t-j}^{2}\right)
\end{gathered}
$$

$D_{t-1}=1$, if $\in_{t-1}<0$, otherwise 0 , if $\in_{t-1} \geq 0$, the conditional volatility appears to be positive when estimates fulfill $\omega_{0}>0, \alpha_{j}+\delta_{j} \geq 0$ and $\beta_{i} \geq 0$ for $i=1, \ldots, p$ and $j=1, \ldots, q$. The GJR-GARCH process is said to be covariance stationery if

$$
\sum_{i=1}^{p} \beta_{i}+\sum_{j=1}^{q}\left(\alpha_{j}+0.5 \delta_{j}\right)<1 .
$$

The one-step-ahead forecast of the GJR-GARCH $(1,1)$ process is

$$
\widehat{h_{t+1}}=\omega+\beta_{1} h_{t}+\alpha_{1} \in_{t}^{2}+\delta 1 \in_{t}^{2} D_{t} .
$$

We store the forecasted variance of various energy market indexes and run regression on the volatility $\left(V O L_{i, t}\right)$ with COVID-19-induced indicators. 


\subsection{Investors' sentiment-based model}

Samuel et al. (2020) explore the likely impact of coronavirus on public sentiment and find that COVID-19 infection has resulted in extreme feelings, emotional and mental healthcare issues. They also detect the presence of high fear, confusion, and volatile sentiments. Bansal (2020) further identifies some of the causes for the recent market crash and increased equity market volatility through the lens of behavioral finance and finds that overconfidence, representative bias, herding behavior, and risk aversion are some of the leading indicators of market turmoil. When investors face a tail event, they rush for their portfolio's protections; mostly futures and options act as a hedge against market adversity. Our study considers widely tracked investors' fear index popularly known as VIX and published in real time. The implied volatility index is expressed in the percentage term, and it is calculated based on the traded market price of the options. We employ three energy market volatility indexes, namely OVX, VXXLE, and OIV. Volatility indexes forecast the future realized volatility with a horizon of 20-22 trading days (Papadamou et al. 2020). The empirical specification to uncover the effects of pandemic infection on the energy market is expressed as

$$
\log I V I i_{i, t}=\tau_{0}+\tau_{1} \text { Return }_{t}^{\text {Underlying }}+\tau_{j 2} D_{j i, t}+e_{t}^{\prime}
$$

where $\log I V I i_{i, t}=\log$-transformed values of OVX, VXXLE, and OIV, $\tau_{0}=$ the intercept coefficient measures the investors' sentiment or level of volatility index during the non-pandemic period; it should be positive and statistically significant. Return $_{t}^{\text {Underlying }}=$ act as a control variable because returns and volatility are inversely associated; the respective underlying of the volatility indexes are USO-ETFs, XLEETF, and WTI futures on which options are written with near-month expiration. $D_{j i, t}=$ the dummy variable that assumes one for the important event under consideration; otherwise, zero. $j=$ Weekly dummies, WHOs announcement, Fed's FOMC statement, GDP, and unemployment report. The slopes associated with $D_{j i, t}$ should appear positive and statistically significant with the fear of COVID-19 infection.

\section{Results and discussion}

\subsection{Pandemic uncertainty and energy markets}

Table 7 shows the regression outcome concerning the pandemic outbreak based on our market model. The intercept coefficient was positive and statistically significant (across Panel A, B, and C) for the WTI, Brent, and DIG-ETF market, which implies an increasing tendency of energy market returns subject to other economic and political events. The intercept estimate of ETFs (i.e., DDG and DUG) appears to be negative and statistically significant, indicating a decreasing tendency of returns following market uncertainty (Lean and Nguyen 2014). Now looking at the excess market returns slope, which appears to be positive (DJUSEN, SPN, WTI, Brent, IYE, and DDG) and more than unity, represents energy market returns sensitivity 


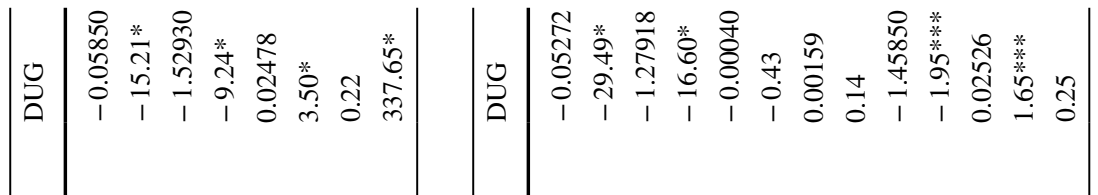

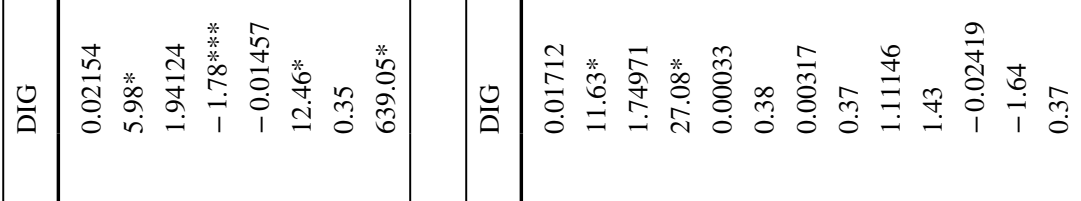

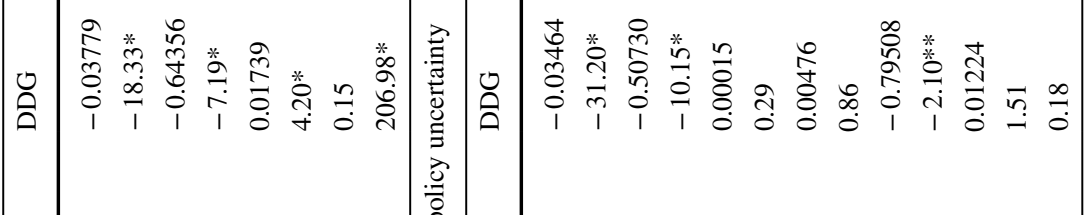

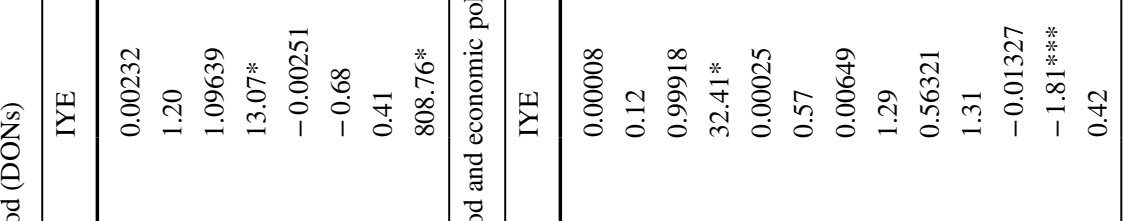

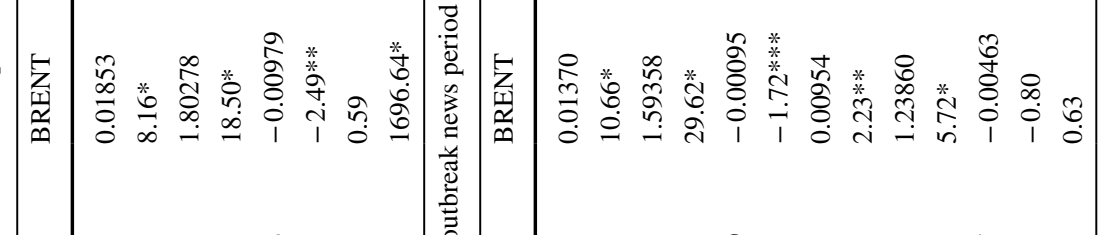

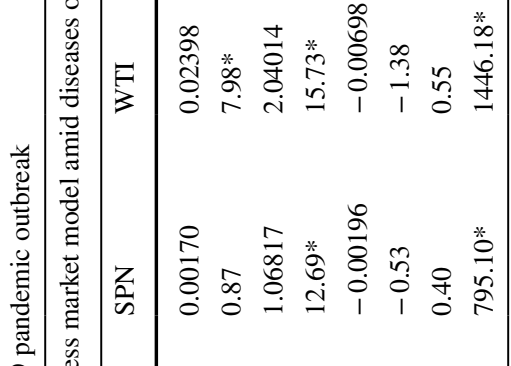

글

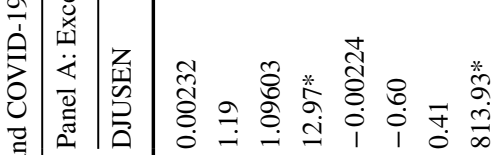

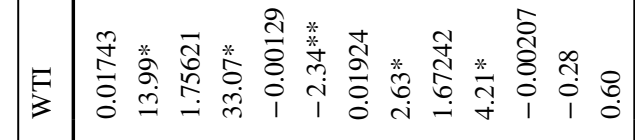




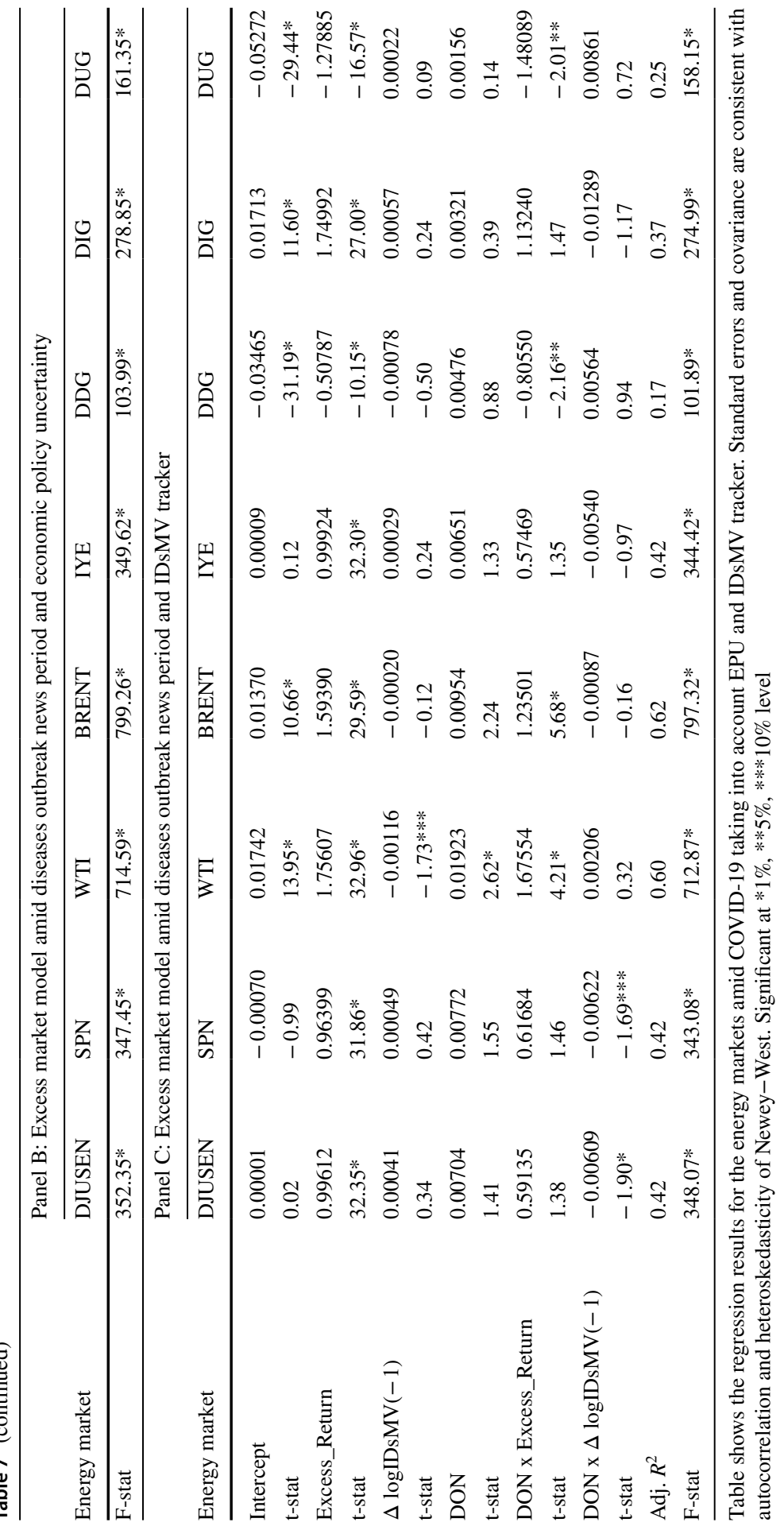


Table 8 Energy markets return behavior during the various phases of COVID-19 infections

\begin{tabular}{|c|c|c|c|c|c|c|c|c|}
\hline $\begin{array}{l}\text { Energy } \\
\text { market }\end{array}$ & DJUSEN & SPN & WTI & BRENT & IYE & DDG & DIG & DUG \\
\hline Intercept & 0.00216 & 0.00154 & 0.02326 & 0.01819 & 0.00210 & -0.03787 & 0.02128 & -0.05855 \\
\hline t-stat & 1.16 & 0.83 & $8.50 *$ & $8.30 *$ & 1.14 & $-19.31 *$ & $6.45^{*}$ & $-15.75^{*}$ \\
\hline $\begin{array}{l}\text { Excess_ } \\
\quad \text { Return }\end{array}$ & 1.08953 & 1.06145 & 2.01129 & 1.79043 & 1.08775 & -0.64972 & 1.93149 & -1.53513 \\
\hline t-stat & $13.51 *$ & $13.17 *$ & $16.97 *$ & $18.97 *$ & $13.59^{*}$ & $-7.60^{*}$ & $13.47 *$ & $-9.57^{*}$ \\
\hline DONs-I & -0.00396 & -0.00377 & -0.00746 & -0.00572 & -0.00370 & 0.01489 & -0.01322 & 0.02414 \\
\hline t-stat & $-1.82 * * *$ & $-1.73 * * *$ & $-5.75^{*}$ & $-3.56^{*}$ & $-1.70 * * *$ & $4.42 *$ & $-2.59 *$ & $4.13 *$ \\
\hline DONs-II & -0.01224 & -0.01150 & -0.03273 & -0.03223 & -0.01304 & 0.03030 & -0.04627 & 0.04169 \\
\hline t-stat & -0.91 & -0.86 & $-6.91^{*}$ & $-6.28^{*}$ & -1.02 & $2.06^{* *}$ & $-1.64 * * *$ & 1.56 \\
\hline DONs-III & 0.01450 & 0.01449 & 0.00956 & -0.00252 & 0.01463 & 0.01027 & 0.01411 & 0.00520 \\
\hline t-stat & $3.30 *$ & $3.29^{*}$ & 0.45 & -0.14 & $3.30 *$ & $2.39 * *$ & $1.67 * * *$ & 0.62 \\
\hline DONs-IV & -0.00658 & -0.00599 & 0.00385 & -0.00568 & -0.00598 & 0.02825 & -0.02363 & 0.04401 \\
\hline t-stat & $-1.86^{* * *}$ & $-1.75^{* * *} *$ & 0.62 & -1.15 & $-1.72 * * *$ & $7.50 *$ & $-3.46^{*}$ & $6.16^{*}$ \\
\hline Adj. $R^{2}$ & 0.42 & 0.41 & 0.56 & 0.60 & 0.41 & 0.16 & 0.36 & 0.23 \\
\hline F-stat & $284.63^{*}$ & $277.84 *$ & $505.99 *$ & $589.28 *$ & $283.17 *$ & $76.30^{*}$ & $229.02 *$ & $119.36^{*}$ \\
\hline
\end{tabular}

Table shows the regression results for the energy markets amid COVID-19 taking into account phases of diseases outbreak news (DONs). Standard errors and covariance are consistent with autocorrelation and heteroskedasticity of Newey-West. Significant at $* 1 \%, * * 5 \%, * * * 10 \%$ level

concerning systematic risk. It implies that the above-mentioned energy markets portfolio is aggressive to market shock and overreaction to the market-wide risk. However, the estimated beta (excess market returns) for the ETFs (DDG and DUG) was calculated adversely and statistically significantly. One of the essential findings is that DDG and DUG funds are less responsive to the market risk and can act as a defensive asset class for risk management. Further, we can see that estimates in relation to the DONs period appear negative for all markets except for DDG and DUG. It indicates that the news about pandemic infections does not matter for the DDG and DUG funds. Unlike studies of Ji et al. (2020), these funds represent a safehaven for ETF investors. Now, moving on to the estimate of DON*Excess Returns, market risk beta was found to be less than unity for the DJUSEN, SPN, IYE, and more than one for the WTI and Brent. Hence, at this point, one can say that crude oil futures are more aggressive to market ups and downs. Moreover, EFTs such as DDG and DUG help the investor in risk aversion. We further examine the effects of economic uncertainty with one-period lag values of EPU; one can see that WTI and Brent market were responding adversely following the recent economic and political announcements. But when looking at the interaction of DON x $\Delta \operatorname{logEPU}(-1)$, pandemic-induced uncertainty negatively impacts the energy market except to certain ETFs (i.e., DDG\&DUG). The last panel represents the behavior of the energy sector amid infectious diseases market volatility (IDsMV). The estimates on the $\Delta$ $\operatorname{logIDsMV}(-1)$ and DON x $\Delta \operatorname{logIDsMV}(-1)$ provide insights that pandemic infections impact the energy market adversely. The next paragraph brings more detailed evidence on the COVID-19-induced uncertainty and energy market performance. 
Table 8 shows the excess market return model results formulated in terms of the diseases outbreak news (DONs) timeline. The timeline DONs-I set to be ranging from January-February 2020, and this is the initial incubation period of outbreak of virus with epicenter Wuhan, China. We can see that contagious infectious diseases have disrupted the major energy market; most slopes appear negative and statistically significant. China has imposed lockdown, social distancing, and travel ban during this period, which has resulted in a decrease in the demand for energy utility; hence, one can see that WTI and Brent, the global crude oil source, affected significantly. One can notice during DONs-I, ETFs (DDG and DUG) outperformed with significant positive returns. The period DON-II is the third month of the first quarter of 2020; during March, the pandemic virus COVID-19 started growing exponentially across Europe, Italy, France, and Germany, which became major COVID-19 victim countries. During this period, furthermost of the energy markets responded adversely, and again DDG and DUG remain resilient through the entire pandemic period. The DONs-III is a period with a rapid outbreak of pandemic in the USA and Asian countries. But looking at the estimates, one can say that during this period energy market rebounded to its original conditions. The DON-IV is the fifth month with some signs of recovery cases in the USA and other countries. DON-III and DON-IV are the period of strict lockdown, domestic and international travel, and transportation that has significantly hampered energy utility demand. Consequently, the cumulative fear and panic in the market affect energy trading adversely, and it is quite apparent from the last row of the table.

Table 9 exhibits a further detailed analysis of the pandemic outbreak's effects in a various phased manner. The results are presented in terms of 15 dummies designated with a particular timeline (see "Appendix D"). December 1, 2019, to January 17, 2020, is assumed with dummy D1, the pandemic COVID-19, the first case reported in China, and the outbreak spread in other countries. During this period, the global standard crude oil market (WTI and Brent) affected significantly, and DJUSEN and SPN energy stocks also exhibited negative returns. When looking at the weekly dummies (DW2-DW15), eight dummies out of 14 appear negative and significant. It implies that weekly pandemic outbreak shock has contributed adversely across energy stocks, crude oil futures, and ETFs trading (Çıtak et al. 2020). But one can see that through DW11-DW15, a weekly update on the COVID-19 further boosted the market sentiment in energy firms (DJUSEN and SPN), while WTI and Brent experienced negative returns. The last three weeks of April 2020 were found as relaxation in the lockdown. The reopening of the markets has with some global political interventions such as suspension of immigration, contractions of China's GDP, and the USA. Moreover, interestingly one can see that again, through most of the pandemic session, exchange-traded funds (DDG and DUG) yield positive returns to energy traders.

Table 10 presents the energy market responses to the WHO's and CDC announcements (see "Appendix C"). Our study mainly considers six major announcements in relation to the COVID-19 outbreak and health emergency steps. The WHO's report's dummies are denoted by DWHO1-5 and US Centers for Disease Control and Prevention with DCDC6. DWHO1 covers the period from January 4, 2020, to January 20, 2020. January 4 is the day on which WHO reported the first case of 
Table 9 Energy markets return behavior amid COVID-19 weekly growth

\begin{tabular}{|c|c|c|c|c|c|c|c|c|}
\hline $\begin{array}{l}\text { Energy } \\
\text { market }\end{array}$ & DJUSEN & SPN & WTI & BRENT & IYE & DDG & DIG & DUG \\
\hline Intercept & 0.00140 & 0.00079 & 0.02352 & 0.01790 & 0.00143 & -0.03606 & 0.01913 & -0.05560 \\
\hline t-stat & 0.85 & 0.49 & $8.67 *$ & $8.38 *$ & 0.87 & $-19.52 *$ & $6.65^{*}$ & $-16.27^{*}$ \\
\hline $\begin{array}{l}\text { Excess_ } \\
\text { Return }\end{array}$ & 1.05882 & 1.03094 & 2.01898 & 1.77782 & 1.05973 & -0.57961 & 1.84565 & -1.42054 \\
\hline t-stat & $14.88^{*}$ & $14.62 *$ & $17.24 *$ & $19.33^{*}$ & $14.92 *$ & $-7.30^{*}$ & $14.84 *$ & $-9.74 *$ \\
\hline D1 & -0.00031 & -0.00027 & -0.00527 & -0.00445 & -0.00146 & 0.00609 & -0.00347 & 0.00976 \\
\hline t-stat & -0.39 & -0.35 & $-3.91 *$ & $-4.14 *$ & -1.48 & $5.11 *$ & $-2.16^{* *}$ & $4.66^{*}$ \\
\hline DW2 & -0.00183 & -0.00153 & -0.00658 & -0.00475 & -0.00172 & 0.01329 & -0.00883 & 0.02041 \\
\hline t-stat & -1.57 & -1.31 & $-4.42 *$ & $-3.60 *$ & -1.51 & $14.68 *$ & $-4.36^{*}$ & $11.49^{*}$ \\
\hline DW3 & -0.00477 & -0.00479 & -0.00329 & -0.00175 & -0.00453 & 0.01822 & -0.01629 & 0.02928 \\
\hline t-stat & $-2.08 * *$ & $-2.03 * *$ & $-1.95^{* * *}$ & $-1.87 * * *$ & $-1.98 * *$ & $7.77 *$ & $-3.49 *$ & $6.25^{*}$ \\
\hline DW4 & 0.00142 & 0.00164 & -0.01128 & -0.01786 & 0.00149 & 0.00839 & -0.00200 & 0.01231 \\
\hline t-stat & 0.64 & 0.76 & $-9.55^{*}$ & $-3.94^{*}$ & 0.67 & $3.38^{*}$ & -0.46 & $2.51 * *$ \\
\hline DW5 & -0.00293 & -0.00245 & -0.00587 & -0.00003 & -0.00152 & 0.01073 & -0.00753 & 0.01685 \\
\hline t-stat & $-1.65^{* * *}$ & -1.29 & $-3.97^{*}$ & -0.01 & -0.88 & $4.90^{*}$ & $-2.18^{*}$ & $5.01 *$ \\
\hline DW6 & -0.00460 & -0.00433 & -0.00692 & -0.00549 & -0.00462 & 0.01422 & -0.01369 & 0.02501 \\
\hline t-stat & $-3.40^{*}$ & $-3.30 *$ & $-3.10^{*}$ & $-3.15^{*}$ & $-3.45^{*}$ & $8.60^{*}$ & $-5.17^{*}$ & $8.11^{*}$ \\
\hline DW7 & -0.01826 & -0.01825 & -0.01511 & -0.01036 & -0.01798 & 0.03946 & -0.04922 & 0.06536 \\
\hline t-stat & $-2.87^{*}$ & $-2.92 *$ & $-11.52 *$ & $-7.13^{*}$ & $-2.74^{*}$ & $7.39 *$ & $-3.91 *$ & $5.77^{*}$ \\
\hline DW8 & -0.01453 & -0.01309 & -0.02495 & -0.02802 & -0.01453 & 0.03498 & -0.04068 & 0.05679 \\
\hline t-stat & $-4.13^{*}$ & $-3.67 *$ & $-5.80 *$ & $-8.78 *$ & $-4.44^{*}$ & $5.25^{*}$ & $-4.66^{*}$ & $5.26^{*}$ \\
\hline DW9 & -0.03735 & -0.03674 & -0.02991 & -0.03629 & -0.03778 & 0.05759 & -0.11033 & 0.08076 \\
\hline t-stat & $-1.86^{* * *}$ & $-1.90^{* * *}$ & $-1.66^{* * *}$ & $-2.01 * *$ & $-1.90^{* * *}$ & $3.24^{*}$ & $-2.70^{*}$ & $2.24 * *$ \\
\hline DW10 & -0.02585 & -0.02652 & -0.04805 & -0.02499 & -0.02577 & 0.03872 & -0.07403 & 0.06723 \\
\hline t-stat & $-2.15^{* *}$ & $-2.18^{*}$ & $-3.99 *$ & $-3.89 *$ & $-2.19^{* *}$ & $2.71^{*}$ & $-3.32 *$ & $2.76^{*}$ \\
\hline DW11 & 0.01734 & 0.01903 & -0.03043 & -0.03337 & 0.01419 & -0.00331 & 0.01470 & -0.02742 \\
\hline t-stat & 1.41 & 1.53 & $-4.55^{*}$ & $-11.73^{*}$ & 1.23 & -0.23 & 0.63 & -0.95 \\
\hline DW12 & 0.00621 & 0.00721 & 0.03293 & 0.04518 & 0.00614 & 0.01467 & -0.00072 & 0.01693 \\
\hline t-stat & 1.27 & 1.48 & $1.72 * * *$ & $1.89 * * *$ & 1.25 & $2.76^{*}$ & -0.08 & $1.85^{* * *}$ \\
\hline DW13 & 0.03035 & 0.02998 & -0.07203 & -0.03327 & 0.03026 & -0.00855 & 0.04823 & -0.03128 \\
\hline t-stat & $6.24 *$ & $5.92 *$ & $-6.67^{*}$ & $-6.95^{*}$ & $5.69 *$ & -1.52 & $5.21 *$ & $-2.99^{*}$ \\
\hline DW14 & 0.00678 & 0.00679 & -0.04690 & -0.02347 & 0.00724 & 0.01848 & -0.00311 & 0.01922 \\
\hline t-stat & 0.72 & 0.70 & $-6.60^{*}$ & $-5.38^{*}$ & 0.76 & $1.71 * * *$ & -0.17 & 0.85 \\
\hline DW15 & 0.01840 & 0.01806 & 0.05543 & -0.01321 & 0.01828 & 0.00821 & 0.02207 & 0.00270 \\
\hline t-stat & $3.64 *$ & $3.60 *$ & $2.39 * *$ & -0.64 & $3.50 *$ & $2.18 * *$ & $2.44 * *$ & 0.35 \\
\hline Adj. $R^{2}$ & 0.43 & 0.43 & 0.59 & 0.61 & 0.43 & 0.16 & 0.38 & 0.23 \\
\hline F-stat & $114.10^{*}$ & $112.02 *$ & $217.65^{*}$ & $231.27 *$ & $113.01 *$ & $28.63^{*}$ & $94.01 *$ & $46.26^{*}$ \\
\hline
\end{tabular}

Table shows the regression results for the energy markets amid COVID-19 taking into account diseases outbreak news (DONs) with weekly updates and administrative actions. Standard errors and covariance are consistent with autocorrelation and heteroskedasticity of Newey-West. Significant at $* 1 \%$, * $5 \%$, *** $10 \%$ level 
Table 10 Energy markets return behavior during the WHOs announcements and CDC actions

\begin{tabular}{|c|c|c|c|c|c|c|c|c|}
\hline $\begin{array}{l}\text { Energy } \\
\text { market }\end{array}$ & DJUSEN & SPN & WTI & BRENT & IYE & DDG & DIG & DUG \\
\hline Intercept & 0.00212 & 0.00150 & 0.02374 & 0.01850 & 0.00208 & -0.03777 & 0.02130 & -0.05829 \\
\hline t-stat & 1.06 & 0.75 & $8.03 *$ & $8.16^{*}$ & 1.05 & $-18.59 *$ & $5.88 *$ & $-15.24 *$ \\
\hline $\begin{array}{l}\text { Excess_ } \\
\text { Return }\end{array}$ & 1.08778 & 1.05994 & 2.03184 & 1.80339 & 1.08689 & -0.64534 & 1.93272 & -1.52447 \\
\hline t-stat & $12.54^{*}$ & $12.24 *$ & $15.87 *$ & $18.47 *$ & $12.58^{*}$ & $-7.29 *$ & $12.27 *$ & $-9.23 *$ \\
\hline DWHO1 & -0.00079 & -0.00064 & -0.00825 & -0.00544 & -0.00084 & 0.00856 & -0.00536 & 0.01361 \\
\hline t-stat & -0.89 & -0.70 & $-3.16^{*}$ & $-2.12 * *$ & -0.98 & $9.52 *$ & $-2.99 *$ & $7.45^{*}$ \\
\hline DWHO2 & -0.00352 & -0.00328 & -0.00363 & -0.00306 & -0.00326 & 0.01630 & -0.01307 & 0.02586 \\
\hline t-stat & $-3.95^{*}$ & $-3.75^{*}$ & $-2.51 * *$ & $-1.82 * * *$ & $-3.66^{*}$ & $15.72 *$ & $-7.34^{*}$ & $13.62 *$ \\
\hline DWHO3 & -0.00057 & -0.00033 & -0.01034 & -0.01475 & -0.00016 & 0.01196 & -0.00635 & 0.01811 \\
\hline t-stat & -0.30 & -0.17 & $-12.51^{*}$ & $-7.27 *$ & -0.09 & $5.51 *$ & $-1.70 * * *$ & $4.32 *$ \\
\hline DWHO4 & -0.01664 & -0.01586 & -0.01901 & -0.01733 & -0.01647 & 0.03189 & -0.04585 & 0.05134 \\
\hline t-stat & $-2.46^{*}$ & $-2.48^{*}$ & $-2.20 * *$ & $-1.72 * * *$ & $-2.39 * *$ & $3.50^{*}$ & $-2.50^{* *}$ & $3.67 *$ \\
\hline DWHO5 & 0.00262 & 0.00284 & -0.00202 & -0.00963 & 0.00261 & 0.01876 & -0.01020 & 0.02228 \\
\hline t-stat & 0.40 & 0.43 & -0.17 & -1.22 & 0.41 & $3.15^{*}$ & -0.78 & $1.93 * * *$ \\
\hline DCDC6 & -0.00123 & -0.00077 & -0.01109 & -0.01537 & -0.00126 & 0.02483 & -0.01388 & 0.03717 \\
\hline t-stat & -0.25 & -0.16 & $-3.85^{*}$ & $-3.29 *$ & -0.26 & $5.63^{*}$ & -1.52 & $4.09 *$ \\
\hline Adj. $R^{2}$ & 0.41 & 0.40 & 0.55 & 0.59 & 0.41 & 0.16 & 0.36 & 0.22 \\
\hline F-stat & $239.67 *$ & $233.96 *$ & $416.32 *$ & $487.67 *$ & $237.75^{*}$ & $64.19^{*}$ & $190.31 *$ & $101.01 *$ \\
\hline
\end{tabular}

Table shows the regression results for the energy markets amid COVID-19 taking into account WHOs announcements and CDC actions. Standard errors and covariance are consistent with autocorrelation and heteroskedasticity of Newey-West. Significant at *1\%, **5\%, ***10\% level

unknown pneumonia and death. One can see that the news outbreak has negatively impacted the crude oil trading and further ETFs-DIG, but DDG and DUG keep on outperforming during the initial period of a pandemic outbreak. DWHO2 denotes the dummy that captures the pandemic phase from January 21, 2020, to January 28,2020 , a period of sluggish infection in the USA. On January 21, the US State Department of Health, Washington, announced the first case of COVID-19 with Wuhan, China's travel history. The spread of news significantly disrupted the energy stocks and global trade of crude oil. DWHO3 measures the energy market response after WHO has declared a novel coronavirus outbreak (COVID-19) as one of the public health emergencies of international concern. WHO report a novel coronavirus on January 30, 2020, and this news has further reduced the energy market and futures price of Crude oil. DWHO4 denotes the day (February 11, 2020) on which WHO formally announced a new form of virus COVID-19; the degree of overreaction appears to be very disappointing for the energy markets. DWHO5 shows the measurement of the recent coronavirus announcement as a pandemic infectious outbreak on March 11, 2020. Finally, the DCDC6 dummy measures the CDC's action and the reporting of COVID-19 infections and the death of about 100,000 people in the USA. Again, this news further disrupted the energy stocks and trading of the crude oil futures. An essential observation from Table 10 is that through the entire 
Table 11 Energy markets return behavior during the Fed's announcements

\begin{tabular}{|c|c|c|c|c|c|c|c|c|}
\hline $\begin{array}{l}\text { Energy } \\
\text { market }\end{array}$ & DJUSEN & SPN & WTI & BRENT & IYE & DDG & DIG & DUG \\
\hline Intercept & 0.00177 & 0.00113 & 0.02238 & 0.01752 & 0.00174 & -0.03703 & 0.02025 & -0.05707 \\
\hline t-stat & 1.07 & 0.69 & $8.81^{*}$ & $8.64 *$ & 1.05 & $-20.76^{*}$ & $7.02 *$ & $-17.16^{*}$ \\
\hline $\begin{array}{l}\text { Excess_ } \\
\text { Return }\end{array}$ & 1.07625 & 1.04746 & 1.97850 & 1.76589 & 1.07557 & -0.62516 & 1.89842 & -1.49090 \\
\hline t-stat & $14.94 *$ & $14.64 *$ & $17.93^{*}$ & $20.18^{*}$ & $14.99 *$ & $-7.97 *$ & $15.05^{*}$ & $-10.33^{*}$ \\
\hline DFED1 & -0.02045 & -0.01961 & -0.02649 & -0.02949 & -0.02043 & 0.04170 & -0.06365 & 0.05988 \\
\hline t-stat & $-1.89^{* * *}$ & $-1.85^{* * *}$ & $-3.30^{*}$ & $-3.66^{*}$ & $-1.89^{* * *}$ & $3.83 *$ & $-2.59^{* *}$ & $3.03^{*}$ \\
\hline DFED2 & -0.02574 & -0.02642 & -0.04802 & -0.02494 & -0.02565 & 0.03845 & -0.07372 & 0.06678 \\
\hline t-stat & $-2.16^{* *}$ & $-2.19 * *$ & $-3.95^{*}$ & $-3.84 *$ & $-2.20 * *$ & $2.75 *$ & $-3.37 *$ & $2.80 *$ \\
\hline DFED3 & 0.01858 & 0.01967 & -0.01201 & -0.00162 & 0.01760 & 0.00003 & 0.02106 & -0.01621 \\
\hline t-stat & $3.40 *$ & $3.58 *$ & -1.15 & -0.10 & $3.21 *$ & 0.01 & $1.91 * * *$ & -1.16 \\
\hline DFED4 & 0.01462 & 0.01431 & -0.01052 & -0.02996 & 0.01468 & 0.01409 & 0.01345 & 0.01153 \\
\hline t-stat & $1.92 * * *$ & $1.84 * * *$ & -0.40 & $-4.29 *$ & $1.89 * * *$ & $1.97 * * *$ & 0.91 & 0.81 \\
\hline DFED5 & -0.00964 & -0.00888 & 0.05479 & 0.02033 & -0.00982 & 0.02847 & -0.03069 & 0.04513 \\
\hline t-stat & -1.63 & -1.53 & 1.27 & 1.42 & $-1.68 * * *$ & $4.73^{*}$ & $-2.71 *$ & $3.67 *$ \\
\hline DFED6 & -0.00386 & -0.00346 & 0.00113 & -0.00879 & -0.00316 & 0.02489 & -0.01762 & 0.03786 \\
\hline t-stat & -1.13 & -1.02 & 0.17 & $-1.90 * * *$ & -0.96 & $6.86^{*}$ & $-2.74 *$ & $5.46^{*}$ \\
\hline Adj. $R^{2}$ & 0.42 & 0.42 & 0.57 & 0.60 & 0.43 & 0.16 & 0.37 & 0.23 \\
\hline F-stat & $253.43^{*}$ & $248.77 *$ & $448.07 *$ & $510.12 *$ & $250.83^{*}$ & $63.58^{*}$ & $203.57 *$ & $102.71 *$ \\
\hline
\end{tabular}

Table shows the regression results for the energy markets amid COVID-19 taking into account Fed's announcements. Standard errors and covariance are consistent with autocorrelation and heteroskedasticity of Newey-West. Significant at $* 1 \%, * * 5 \%$, ***10\% level

WHO's announcements and pandemic infections, the ETFs (DDG \& DUG) remain indifferent and yield optimistic energy traders' yield.

Table 11 describes the energy market response to the federal announcements and macroeconomic outlook amid COVID-19 uncertainty. Our study mainly covers the FOMC statements, Federal fund rate changes, and macroeconomic report releases during the pandemic period. In order to combat such pandemic, crises administration declares put protection, bailout package, quantitative easing $(\mathrm{QE})$, so as eventually market can revert to the normalcy. Hence, federal support and ease of monetary policy should show a positive shock on the energy markets. We create six dummies (DFED1-6) that capture the Federal reserve the day of the announcement and surrounding period. DFED1 measures the response of the energy market from February 28 to March 14, 2020. During this period, Fed started a review of the current economic development and combating the risk of corona infection to economic activity. Fed called an unscheduled FOMC meeting on March 3, 2020, and decided to lower the fund rates by 50 basis points. Looking at the estimates, one can see that the energy market remains insensitive to Fed's announcements and overreaction with a negative return. DFED2 denoted further actions from the Fed on March 15, 2020. FOMC committee took three essential steps: lower fund rate 100 basis point, credit support for the household, and swap line with the world's major central banks of 
the US dollar liquidity. Again, we find a negative impact of such actions on the energy stocks, crude oil futures, and some ETFs. DFED3 considered the Fed's new measures to support the economic activity on March 23, 2020. It consists of creating more liquidity in the economy through a bond-buying program and planned to inject up to $\$ 300$ billion in the financial system. One can see that this announcement has created a positive sentiment in the market and lifted the energy stocks (DJUSEN and SPN), but WTI and Brent experience negative returns. Most of the ETFs responded positively to the Fed's action. DFED4 assumes the Fed's declaration (April 9) of \$2.3 trillion loan support to boost the financial institutions' liquidity and assistance to the household and employees. Historically, this was the most significant bailout package to support economic activity. One can see that most energy market indicators appeared with positive returns, yet crude oil was struggling. DFED5 set to measure the effects of GDP on the energy markets announced on April 29. The real GDP fell by $4.8 \%$ in the first quarter of 2020. The news has further disappointed the market. Lastly, DFED6 gauges the effects of a report from the Bureau of Labour Statistics on non-farm employment data. There has been a rise of about $14.7 \%$ unemployment. The energy market has exhibited adversely that the crude oil futures Brent and ETFs-DIG have shown significant negative response to the massive job loss.

\subsection{Modeling the energy market volatility amid COVID-19}

Figure 4 exhibits the time series plot of the energy markets' volatility during the pandemic period (December 29, 2019-May 31, 2020). We model the conditional volatility for the sample using the GJR-GARCH model. Most of the energy indexes start experiencing a spike in volatility by the end of February and reach their peak level in March. COVID-19-induced volatility is more pronounced in the crude oil futures market. Energy stock indexes and ETFs do have one wave of pandemicinduced volatility, while WTI and Brent do have two waves. The crude oil futures market starts exhibiting volatility from March and remains higher through and fall in April, but again, it has crossed the previous peak in May. We present how the pandemic outbreak timeline, WHO's and Fed's announcements increased the level of ex post energy market volatility.

Table 12 presents the movement of the energy market volatility during pandemic growth. We can see that most of the energy market indicators show a positive intercept coefficient, which implies that except for COVID-19-induced uncertainty, some other economic and political factors have increased the energy market volatility. Further, we regress with weekly dummies (see "Appendix D") and find that COVID19 cases and action to combat the pandemic crises have disrupted the energy market, which has resulted in an increased level of historical volatility. Moreover, in many instances, ETFs (DDG and DUG) experience a low degree of rising return volatility. Table 13 demonstrates the response of the energy market's volatility amid WHO's announcement. One can see that across all asset classes intercept coefficient appears positive and statistically significant. It indicates that economic and political 
DJUSEN-Volatility

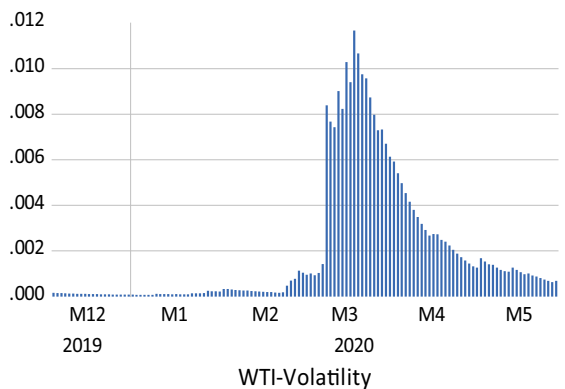

.020

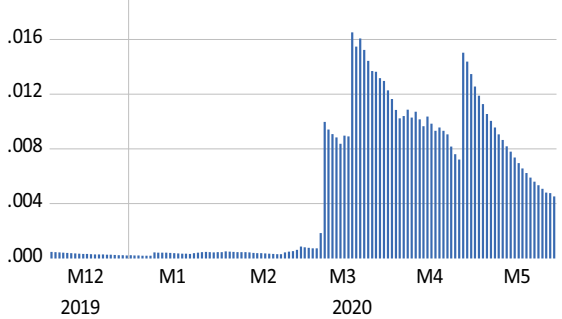

IYE-Volatility
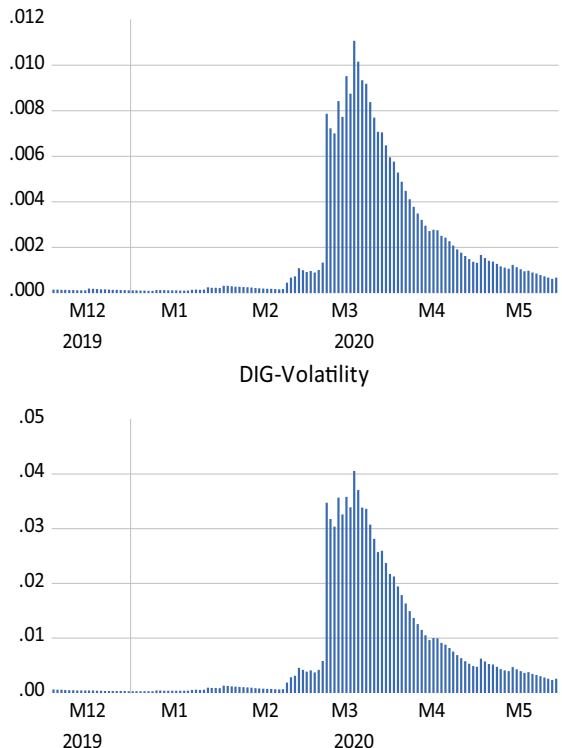

SPN-Volatility
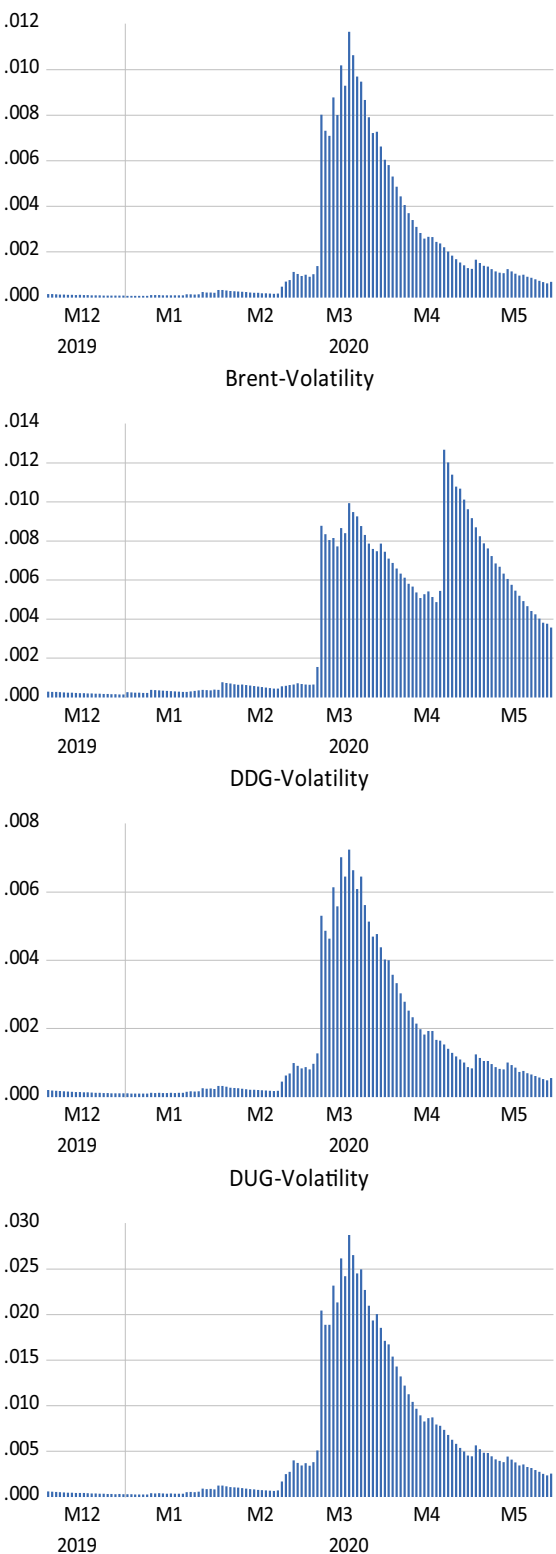

Fig. 4 GJR-GARCH volatility during the COVID-19 infections period

uncertainty is operative to explain the energy market volatility. We can see that market was under normal state during the first two announcements from the WHO. In comparison, the next four reports have shown unprecedented overreaction of the energy market with an increased level of ex post volatility. The significant positive 
Table 12 Energy market volatility amid COVID-19 weekly growth

\begin{tabular}{|c|c|c|c|c|c|c|c|c|}
\hline & DJUSEN & SPN & WTI & BRENT & IYE & DDG & DIG & DUG \\
\hline Energy market & VOL1 & VOL2 & VOL3 & VOL4 & VOL5 & VOL6 & VOL7 & VOL8 \\
\hline Intercept & 0.00020 & 0.00019 & 0.00071 & 0.00058 & 0.00020 & 0.00027 & 0.00079 & 0.00094 \\
\hline t-stat & $6.69 *$ & $6.26^{*}$ & 0.64 & 0.71 & $6.56^{*}$ & 1.40 & $7.34 *$ & 1.09 \\
\hline DW1 & -0.00008 & -0.00007 & 0.00031 & 0.00012 & -0.00005 & 0.00011 & -0.00033 & 30.00034 \\
\hline t-stat & -0.16 & -0.14 & 0.23 & 0.23 & -0.09 & 0.87 & -0.18 & 0.72 \\
\hline DW2 & -0.00005 & -0.00004 & 0.00036 & 0.00020 & -0.00002 & 0.00022 & -0.00022 & 20.00070 \\
\hline t-stat & -0.06 & -0.06 & 0.22 & 0.29 & -0.03 & 1.38 & -0.07 & 1.12 \\
\hline DW3 & 0.00002 & 0.00003 & 0.00046 & 0.00032 & 0.00006 & 0.00034 & 0.00004 & 0.00109 \\
\hline t-stat & 0.04 & 0.06 & 0.26 & 0.42 & 0.13 & $1.85^{* * *}$ & 0.02 & 1.52 \\
\hline DW4 & 0.00021 & 0.00023 & 0.00052 & 0.00039 & 0.00025 & 0.00055 & 0.00072 & 0.00187 \\
\hline t-stat & 0.62 & 0.73 & 0.29 & 0.48 & 0.92 & $2.71^{*}$ & 0.50 & $2.36^{*}$ \\
\hline DW5 & 0.00034 & 0.00037 & 0.00057 & 0.00046 & 0.00041 & 0.00065 & & 0.00219 \\
\hline t-stat & $1.71 * * *$ & $1.93 * * *$ & 0.33 & 0.55 & $2.37 * *$ & $3.09 *$ & 1.43 & $2.60 *$ \\
\hline DW6 & 0.00067 & 0.00070 & 0.00062 & 0.00053 & 0.00076 & 0.00076 & 0.00232 & 0.00252 \\
\hline t-stat & $5.19 *$ & $5.60 *$ & 0.37 & 0.63 & $6.39 *$ & $3.53 *$ & $4.61 *$ & $2.88^{*}$ \\
\hline DW7 & 0.00145 & 0.00148 & 0.00068 & 0.00062 & 0.00152 & 0.00089 & 0.00529 & 0.00297 \\
\hline t-stat & $16.27 *$ & $16.82 *$ & 0.44 & 0.75 & $17.79 *$ & $4.09 *$ & $15.63 *$ & $3.30 *$ \\
\hline DW8 & 0.00275 & 0.00273 & 0.00099 & 0.00078 & 0.00271 & 0.00094 & 0.01027 & 0.00306 \\
\hline t-stat & $44.57 *$ & $44.60 *$ & 0.74 & 1.00 & $44.19 *$ & $4.20^{*}$ & $45.06^{*}$ & $3.24 *$ \\
\hline DW9 & 0.00574 & 0.00558 & 0.00218 & 0.00179 & 0.00527 & 0.00138 & 0.02220 & 0.00475 \\
\hline t-stat & $128.49^{*}$ & $124.92 *$ & 2.08 & $2.45 * *$ & $114.92 *$ & $6.05^{*}$ & $135.70^{*}$ & $4.85^{*}$ \\
\hline DW10 & 0.00704 & 0.00687 & 0.00178 & 0.00145 & 0.00637 & 0.00093 & 0.02616 & 0.00325 \\
\hline t-stat & $174.61^{*}$ & $171.66^{*}$ & $2.75^{*}$ & $1.72 * * *$ & $153.28 *$ & $2.36^{* *}$ & $156.44^{*}$ & $2.38 * *$ \\
\hline DW11 & 0.00648 & 0.00631 & 0.00243 & 0.00129 & 0.00595 & 0.00046 & 0.02368 & 0.00151 \\
\hline t-stat & $111.63^{*}$ & $111.04 *$ & $3.64 *$ & 1.43 & $101.36^{*}$ & 1.14 & $103.93^{*}$ & 1.08 \\
\hline DW12 & 0.00565 & 0.00553 & 0.00198 & 0.00123 & 0.00527 & 0.00060 & 0.02050 & 0.00239 \\
\hline t-stat & $107.72 *$ & $107.49 *$ & $2.99 *$ & 1.30 & $99.23 *$ & 1.39 & $100.74 *$ & $1.66^{* * * *}$ \\
\hline DW13 & 0.00407 & 0.00398 & 0.00136 & 0.00099 & 0.00389 & 0.00040 & 0.01471 & 0.00145 \\
\hline t-stat & $84.82 *$ & $84.49 *$ & $2.27 * *$ & 1.05 & $82.73 *$ & 0.79 & $78.33^{*}$ & 0.95 \\
\hline DW14 & 0.00270 & 0.00262 & 0.00078 & 0.00072 & 0.00263 & 0.00025 & 0.00973 & 0.00077 \\
\hline t-stat & $60.83^{*}$ & $60.85^{*}$ & 1.59 & 0.94 & $64.88 *$ & 0.31 & $54.44^{*}$ & 0.45 \\
\hline DW15 & 0.00141 & 0.00138 & 0.00098 & 0.00047 & 0.00137 & 0.00002 & 0.00515 & 0.00006 \\
\hline t-stat & $45.01^{*}$ & $45.30^{*}$ & $3.52^{*}$ & $1.91 * * *$ & $49.60 *$ & 0.02 & $40.90^{*}$ & 0.03 \\
\hline Adj. $R^{2}$ & 0.74 & 0.69 & 0.71 & 0.68 & 0.89 & 0.83 & 0.88 & 0.87 \\
\hline F-stat & $1618.36^{*}$ & $1651.95^{*}$ & $398.12 *$ & $338.74 *$ & $1595.22 *$ & $810.43 *$ & $1416.82 *$ & $1145.49 *$ \\
\hline
\end{tabular}

Table shows the regression results for the energy markets' volatility amid COVID-19 taking into account weekly growth of the infection. Standard errors and covariance are consistent with autocorrelation and heteroskedasticity of Newey-West. Significant at $* 1 \%, * * 5 \%, * * * 10 \%$ level 
Table 13 Energy market volatility during the WHOs announcements and CDC actions

\begin{tabular}{lllllllll}
\hline & DJUSEN & SPN & WTI & BRENT & IYE & DDG & DIG & DUG \\
\hline $\begin{array}{l}\text { Energy } \\
\text { market }\end{array}$ & VOL1 & VOL2 & VOL3 & VOL4 & VOL5 & VOL6 & VOL7 & VOL8 \\
Intercept & 0.00019 & 0.00018 & 0.00045 & 0.00039 & 0.00019 & 0.00022 & 0.00074 & 0.00072 \\
t-stat & $19.16^{*}$ & $18.75^{*}$ & $20.68^{*}$ & $21.36^{*}$ & $19.86^{*}$ & $19.68^{*}$ & $18.80^{*}$ & $20.51^{*}$ \\
DWHO1 & -0.00010 & -0.00010 & -0.00013 & -0.00009 & -0.00009 & -0.00012 & -0.00042 & -0.00040 \\
t-stat & $-9.47^{*}$ & $-9.42^{*}$ & $-3.23^{*}$ & $-3.71^{*}$ & $-8.83^{*}$ & $-9.82^{*}$ & $-9.74^{*}$ & $-10.45^{*}$ \\
DWHO2 & -0.00003 & -0.00003 & -0.00006 & -0.00007 & -0.00003 & -0.00005 & -0.00015 & -0.00015 \\
t-stat & $-1.67^{* * *}$ & -1.59 & $-2.08^{* *}$ & $-2.85^{*}$ & $-1.67^{* * *}$ & $-2.43^{* *}$ & $-1.86^{* * *}$ & $-1.93^{* * *}$ \\
DWHO3 & 0.00008 & 0.00009 & 0.00000 & 0.00019 & 0.00008 & 0.00005 & 0.00032 & 0.00031 \\
t-stat & $6.37^{*}$ & $6.72^{*}$ & -0.08 & $3.17^{*}$ & $6.14^{*}$ & $3.85^{*}$ & $6.12^{*}$ & $6.46^{*}$ \\
DWHO4 & 0.00075 & 0.00074 & 0.00055 & 0.00063 & 0.00070 & 0.00053 & 0.00308 & 0.00222 \\
t-stat & 1.55 & 1.58 & 1.06 & 1.50 & 1.54 & 1.55 & 1.53 & $1.66^{* * *}$ \\
DWHO5 & 0.00416 & 0.00410 & 0.01026 & 0.00727 & 0.00403 & 0.00268 & 0.01509 & 0.01142 \\
t-stat & $3.27^{*}$ & $3.26^{*}$ & $14.59^{*}$ & $12.92^{*}$ & $3.37^{*}$ & $3.30^{*}$ & $3.29 *$ & $3.73^{*}$ \\
DCDC6 & 0.00060 & 0.00060 & 0.00483 & 0.00379 & 0.00058 & 0.00038 & 0.00220 & 0.00215 \\
t-stat & $11.42^{*}$ & $11.53^{*}$ & $20.34^{*}$ & $20.38^{*}$ & $11.85^{*}$ & $10.36^{*}$ & $11.15^{*}$ & $12.81^{*}$ \\
Adj. R ${ }^{2}$ & 0.56 & 0.56 & 0.88 & 0.85 & 0.58 & 0.52 & 0.56 & 0.60 \\
F-stat & $527.23^{*}$ & $527.91^{*}$ & $3010.70^{*}$ & $2404.21^{*}$ & $557.04^{*}$ & $443.38^{*}$ & $505.96^{*}$ & $618.76^{*}$ \\
\hline
\end{tabular}

Table shows the regression results for the energy markets' volatility amid COVID-19 taking into account WHOs announcements and CDC actions. Standard errors and covariance are consistent with autocorrelation and heteroskedasticity of Newey-West. Significant at $* 1 \%, * * 5 \%, * * * 10 \%$ level]

slope implies WHO-DONs matter for the energy market performance. Table 14 displays the response of energy market volatility during the Federal reserve's major actions, here expressed in terms of FOMC meeting and fund rate change, GDP, and unemployment data. We can see that estimates across all Fed's dummy stood positive and statistically significant. It indicates that Federal actions to combat the COVID-19 crisis fail to control the overreaction of the energy market's performance.

\subsection{Investors' fear and panic in the energy market during the pandemic outbreak}

Table 15 explains the behavior of the investors' sentiment amid COVID-19. Here, OVX, VXXLE, and OIV are the measures of ex ante energy markets' volatility expressed in percentage term. Let's see the constant, which is found to be positive and statistically significant. It means the non-pandemic period also stood uncertain for the energy market. Looking at the first two dummies, one can say that near month energy market volatility remains lower and approaching normalcy. OVX is the implied volatility index based on the ETFs-USO options and appears to be on the higher side through pandemic development. VXXLE is the volatility index based on ETFs-XLE options, which is also growing weekly since the last week of February. OIV also exhibits the future volatility of crude oil-based trading on options written on the WTI Futures (OL). The significant positive slope 
Table 14 Energy market volatility during the Fed's announcements

\begin{tabular}{lllllllll}
\hline & DJUSEN & SPN & WTI & BRENT & IYE & DDG & DIG & DUG \\
\hline $\begin{array}{l}\text { Energy } \\
\text { market }\end{array}$ & VOL1 & VOL2 & VOL3 & VOL4 & VOL5 & VOL6 & VOL7 & VOL8 \\
Intercept & 0.00019 & 0.00018 & 0.00045 & 0.00039 & 0.00019 & 0.00022 & 0.00075 & 0.00072 \\
t-stat & $19.46^{*}$ & $19.04^{*}$ & $20.96^{*}$ & $21.73^{*}$ & $20.18^{*}$ & $19.96^{*}$ & $19.08^{*}$ & $20.81^{*}$ \\
DFED1 & 0.00344 & 0.00333 & 0.00351 & 0.00314 & 0.00324 & 0.00229 & 0.01406 & 0.00913 \\
t-stat & $2.30^{* *}$ & $2.32^{* *}$ & $1.96^{* *}$ & $1.96^{* *}$ & $2.31^{* *}$ & $2.48^{* *}$ & $2.31^{* *}$ & $2.58^{*}$ \\
DFED2 & 0.00987 & 0.00978 & 0.01120 & 0.00846 & 0.00926 & 0.00637 & 0.03525 & 0.02467 \\
t-stat & $31.29^{*}$ & $28.93^{*}$ & $10.15^{*}$ & $35.36^{*}$ & $28.76^{*}$ & $49.33^{*}$ & $49.52^{*}$ & $37.38^{*}$ \\
DFED3 & 0.00661 & 0.00654 & 0.01228 & 0.00712 & 0.00640 & 0.00423 & 0.02336 & 0.01774 \\
t-stat & $7.37^{*}$ & $7.24^{*}$ & $13.43^{*}$ & $16.60^{*}$ & $7.63^{*}$ & $7.62^{*}$ & $7.65^{*}$ & $8.85^{*}$ \\
DFED4 & 0.00237 & 0.00232 & 0.00929 & 0.00716 & 0.00239 & 0.00153 & 0.00855 & 0.00735 \\
t-stat & $7.61^{*}$ & $7.77^{*}$ & $29.44^{*}$ & $5.36^{*}$ & $7.83^{*}$ & $7.46^{*}$ & $7.83^{*}$ & $9.16^{*}$ \\
DFED5 & 0.00124 & 0.00122 & 0.01158 & 0.00838 & 0.00126 & 0.00080 & 0.00456 & 0.00418 \\
t-stat & $54.37 *$ & $52.54^{*}$ & $20.23^{*}$ & $24.56^{*}$ & $67.59^{*}$ & $25.34^{*}$ & $50.35^{*}$ & $59.41^{*}$ \\
DFED6 & 0.00077 & 0.00076 & 0.00620 & 0.00480 & 0.00075 & 0.00052 & 0.00282 & 0.00270 \\
t-stat & $7.42^{*}$ & $7.60^{*}$ & $7.55^{*}$ & $7.99^{*}$ & $7.17^{*}$ & $6.44^{*}$ & $7.42^{*}$ & $7.96^{*}$ \\
Adj. R ${ }^{2}$ & 0.83 & 0.84 & 0.88 & 0.83 & 0.84 & 0.77 & 0.81 & 0.83 \\
F-stat & $2044.42^{*}$ & $2112.25^{*}$ & $3124.77^{*}$ & $2050.32^{*}$ & $2090.13^{*}$ & $1373.02^{*}$ & $1743.91^{*}$ & $1970.96^{*}$ \\
\hline
\end{tabular}

Table shows the regression results for the energy markets' volatility amid COVID-19 taking into account Fed's announcements. Standard errors and covariance are consistent with autocorrelation and heteroskedasticity of Newey-West. Significant at $* 1 \%$, ** $5 \%$, ***10\% level

indicates that investors' worries and fear were at an extreme level. In order to hedge energy stocks, investors have paid a higher premium for the put options. ${ }^{4}$ Table 16 shows the investor overreactions to the WHO's announcement, which is gauged in implied volatility indexes. We can see that DWHO4-6 estimates appear favorable and significant and indicate that pandemic outbreak has shown extreme panic and anxiety among the energy traders. The dummy DCDC6 was exceedingly positive and statistically significant, and plausibly it is due to the COVID19 fatality of 100,000 people. Table 17 brings some evidence on the Fed's prompt actions to combat the pandemic outbreak, such as the Federal fund rate set to be 0 to $1 / 4$ percent, $\$ 2.3$ trillion of loan support, treasury, and liquidity ease. Consequently, the Fed's action should create more stability in the market, reducing fear and panic among the market participant. Hence, the energy market's expected

\footnotetext{
${ }^{4}$ During the initial period of pandemic outbreak market shocked with the likely impact of COVID-19, hence investors rush for hedge funds. A put/call ratio more than one implies excessive trading volume in the put options, consequently it led to higher premium on the put options and resulting higher implied volatility. The put/call ratio found to be more than one throughout the first quarter 2020 after the WHO announced COVID-19 as international health emergency. Put/call ratio is the measure of the market sentiment higher the ratio specifies excessive fear in the market.
} 
Table 15 Energy markets' investors' fear and panic amid COVID-19 weekly outbreak

\begin{tabular}{|c|c|c|c|}
\hline Energy market & OVX & VXXLE & OIV \\
\hline Intercept & 3.46142 & 3.09537 & 3.45899 \\
\hline t-stat & $169.34 *$ & $181.88^{*}$ & $143.32 *$ \\
\hline Return & -0.74005 & -1.58116 & 0.57099 \\
\hline t-stat & $-2.25^{* *}$ & $-3.73 *$ & 0.87 \\
\hline DW1 & -0.09307 & -0.21207 & -0.11701 \\
\hline t-stat & $-1.97 * *$ & $-4.93 *$ & $-2.81 *$ \\
\hline DW2 & -0.05179 & -0.26862 & -0.01440 \\
\hline t-stat & $-1.65^{* * *}$ & $-9.44 *$ & -0.40 \\
\hline DW3 & 0.15533 & -0.05006 & 0.19228 \\
\hline t-stat & $7.05^{*}$ & $-2.62 *$ & $7.23 *$ \\
\hline DW4 & 0.18751 & -0.01083 & 0.23250 \\
\hline t-stat & $7.80^{*}$ & -0.57 & $9.21 *$ \\
\hline DW5 & 0.14789 & -0.04555 & 0.15114 \\
\hline t-stat & $6.50 *$ & $-2.45^{* *}$ & $4.54 *$ \\
\hline DW6 & 0.07092 & -0.05402 & 0.06477 \\
\hline t-stat & $3.26^{*}$ & $-2.66^{*}$ & $2.36 * *$ \\
\hline DW7 & 0.32078 & 0.46239 & 0.36322 \\
\hline t-stat & $8.25^{*}$ & $5.07 *$ & $9.99 *$ \\
\hline DW8 & 0.50020 & 0.74541 & 0.53533 \\
\hline t-stat & $17.51^{*}$ & $26.73 *$ & $13.45^{*}$ \\
\hline DW9 & 1.21138 & 1.36811 & 1.30008 \\
\hline t-stat & $28.07 *$ & $22.19 *$ & $33.47 *$ \\
\hline DW10 & 1.53046 & 1.63479 & 1.63273 \\
\hline t-stat & $23.43^{*}$ & $53.62^{*}$ & $25.85^{*}$ \\
\hline DW11 & 1.62693 & 1.49657 & 1.64429 \\
\hline t-stat & $51.71 *$ & $55.52 *$ & $58.03 *$ \\
\hline DW12 & 1.66232 & 1.38174 & 1.58892 \\
\hline t-stat & $54.85^{*}$ & $72.40 *$ & $25.88^{*}$ \\
\hline DW13 & 1.43185 & 1.28001 & 1.61039 \\
\hline t-stat & $58.70 *$ & $45.84 *$ & $55.47 *$ \\
\hline DW14 & 1.23152 & 1.16869 & 1.44909 \\
\hline t-stat & $41.96^{*}$ & $47.65^{*}$ & $47.84 *$ \\
\hline DW15 & 1.78377 & 1.11959 & 3.21921 \\
\hline t-stat & $23.00 *$ & $18.89 *$ & $48.05^{*}$ \\
\hline Adj. $R^{2}$ & 0.27 & 0.29 & 0.31 \\
\hline F-stat & $57.13 *$ & $63.88^{*}$ & $67.14 *$ \\
\hline
\end{tabular}

Table shows the regression results for the energy markets' ex ante volatility (option's implied volatility) amid COVID-19 taking into account weekly growth of the infection. Standard errors and covariance are consistent with autocorrelation and heteroskedasticity of Newey-West. Significant at $* 1 \%, * * 5 \%, * * * 10 \%$ level 
Table 16 Energy markets' investors' fear and panic during the WHOs announcements and CDC actions

\begin{tabular}{lccc}
\hline Energy market & OVX & VXXLE & OIV \\
\hline Intercept & 3.45043 & 3.08567 & 3.43552 \\
t-stat & $176.08^{*}$ & $188.47^{*}$ & $170.92^{*}$ \\
Return & -1.32224 & -2.05912 & 0.23063 \\
t-stat & $-3.89 *$ & $-5.08^{*}$ & 0.51 \\
DWHO1 & -0.00443 & -0.27778 & -0.03976 \\
t-stat & -0.18 & $-6.42^{*}$ & -1.19 \\
DWHO2 & 0.03819 & -0.16519 & 0.09123 \\
t-stat & 0.85 & $-4.03^{*}$ & $2.34 * *$ \\
DWHO3 & 0.19425 & -0.00814 & 0.26273 \\
t-stat & $9.33^{*}$ & -0.47 & $12.14 *$ \\
DWHO4 & 0.34524 & 0.38231 & 0.39636 \\
t-stat & $2.64 *$ & $1.75^{* * *}$ & $2.53^{* *}$ \\
DWHO5 & 1.42724 & 1.22969 & 2.14793 \\
t-stat & $16.02^{*}$ & $12.44^{*}$ & $8.03^{*}$ \\
DCDC6 & 0.91241 & 0.72344 & 2.06087 \\
t-stat & $25.73^{*}$ & $30.21^{*}$ & $99.54^{*}$ \\
Adj. R & 0.32 & 0.33 & 0.49 \\
F-stat & $164.21^{2}$ & $167.35^{*}$ & $327.24 *$ \\
\hline Table & & & \\
\hline
\end{tabular}

Table shows the regression results for the energy markets' ex ante volatility (option's implied volatility) amid COVID-19 taking into account WHOs announcements and CDC actions. Standard errors and covariance are consistent with autocorrelation and heteroskedasticity of Newey-West. Significant at $* 1 \%, * * 5 \%$, ****10\% level

volatility (OVX, VXXLE, OIV) should revert to normalcy. It is apparent from the table that none of the slopes through DFED1-6 appears contrary. It implies that Federal actions amid COVID-19 are unable to reduce the likely impact of the pandemic crisis in the energy markets. The extreme level of ex ante volatility in the energy market indicates more panic among the crude oil traders. There is a shortage of derivatives products to hedge tail events in the energy market. The overburden on the energy options (put options) results in higher options' premiums, consequently higher implied volatility. Hence, exchanges need to be more innovative to offer the diverse nature of derivatives products for energy trading.

\section{Robustness check}

In this section, we further deliberate on the robustness check of the previous section's results. We presented the empirical evidence innovatively amid COVID19 based on the policy uncertainty (EPU), infectious diseases market volatility tracker (IDsMV), and further by taking into account Fed's actions, FOMC statement, GDP, and unemployment report. In this section, we demonstrate the performance of the energy market based on the numbers and calculations of the 
Table 17 Energy markets' investors' fear and panic during the Fed's announcements

\begin{tabular}{lccc}
\hline Energy market & OVX & VXXLE & OIV \\
\hline Intercept & 3.45227 & 3.08430 & 3.43739 \\
t-stat & $178.84^{*}$ & $190.74^{*}$ & $173.61^{*}$ \\
Return & -1.08736 & -1.84259 & -0.21978 \\
t-stat & $-3.40^{*}$ & $-4.28^{*}$ & -0.59 \\
DFED1 & 0.81730 & 1.04642 & 0.87351 \\
t-stat & $4.54^{*}$ & $6.69^{*}$ & $4.88^{*}$ \\
DFED2 & 1.51580 & 1.63441 & 1.59947 \\
t-stat & $21.56^{*}$ & $48.22^{*}$ & $24.47^{*}$ \\
DFED3 & 1.61529 & 1.43091 & 1.63752 \\
t-stat & $50.36^{*}$ & $35.41^{*}$ & $57.97^{*}$ \\
DFED4 & 1.54863 & 1.18410 & 2.38702 \\
t-stat & $12.31^{*}$ & $45.94^{*}$ & $5.42^{*}$ \\
DFED5 & 1.32520 & 0.98803 & 3.21731 \\
t-stat & $20.25^{*}$ & $54.53^{*}$ & $53.29^{*}$ \\
DFED6 & 0.96008 & 0.79162 & 2.18374 \\
t-stat & $21.25^{*}$ & $18.75^{*}$ & $24.95^{*}$ \\
Adj. R & 0.33 & 0.34 & 0.51 \\
F-stat & $167.82^{*}$ & $180.52^{*}$ & $366.86^{*}$ \\
\hline
\end{tabular}

Table shows the regression results for the energy markets' ex ante volatility (option's implied volatility) amid COVID-19 taking into account Fed's announcements. Standard errors and covariance are consistent with autocorrelation and heteroskedasticity of NeweyWest. Significant at $* 1 \%$, **5\%, *** $10 \%$ level

COVID-19 outbreak. We set the following regression model in terms of the total number of cases of COVID-19,

$$
\begin{aligned}
& \left(R_{i, t}-R_{f}\right)=\varphi_{0}+\varphi_{1}(R m, t-R f)+\varphi_{3} \log (1+\text { Total_Covid19_Cases })_{t-1}+e_{t}^{\prime} \\
& \log I V I i_{i, t}=\vartheta_{0}+\vartheta_{1} \operatorname{Re} \text { turn }_{t}^{\text {Underlying }}+\vartheta_{3} \log (1+\text { Total_Covid19_Cases })_{t-1}+e_{t}^{\prime \prime}
\end{aligned}
$$

where $\log (1+\text { Total_Covid19_Cases })_{t-1}$ is the log-transformed COVID-19 daily cases with one period lag. $\log I V I_{i, t}$ is the log-transformed values of implied volatility indexes (OVX, VXXLE, OIV) for the energy market, and $e_{t}^{\prime}$ and $e_{t}^{\prime \prime}$ are the classical white noise process. The slope of Eq. (12) should appear negative, and estimate for Eq. (13) should be calculated positive.

Table 18 shows the impact of COVID-19-confirmed infection cases on the energy markets. First, we can see that market-specific beta appears positive for energy stocks and crude oil futures. WTI and Brent show that slope more than unity indicates overreaction of the crude oil traders to the market movements amid COVID-19 infection. At the same time, DJUSEN and SPN seem to be less aggressive. Once again, ETFs (DDG and DUG) estimates appear negative and statistically significant. It indicates that energy ETFs act as safe-haven in portfolio planning. The news about COVID-19 


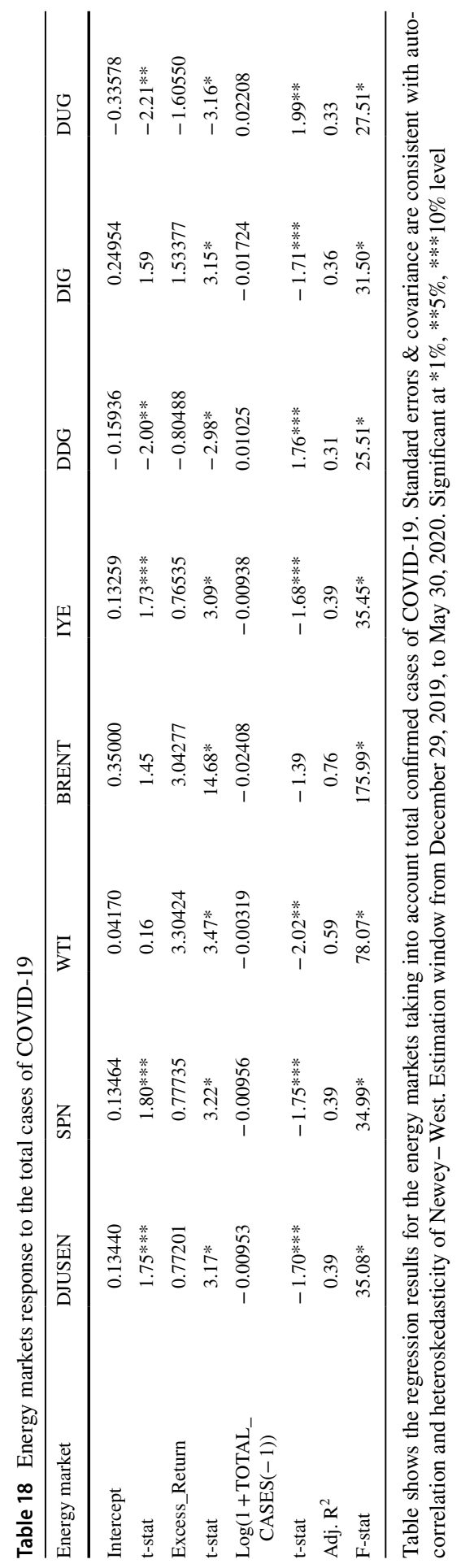


Table 19 Energy markets' investors' fear and anxiety on the total cases of COVID-19

\begin{tabular}{lccc}
\hline Energy market & OVX & VXXLE & OIV \\
\hline Intercept & 3.48126 & 3.03145 & 3.29689 \\
t-stat & $62.11^{*}$ & $30.88^{*}$ & $55.19^{*}$ \\
Return & -2.23017 & -2.34951 & 0.73972 \\
t-stat & $-3.46^{*}$ & $-2.36^{*}$ & 1.05 \\
Log(1+TOTAL_ & 0.10025 & 0.09223 & 0.18038 \\
$\quad$ CASES(-1)) & & & \\
t-stat & $9.81^{*}$ & $8.36^{*}$ & $11.73^{*}$ \\
Adj. R & 0.70 & 0.62 & 0.84 \\
F-stat & $124.84^{*}$ & $86.23^{*}$ & $281.03^{*}$ \\
\hline
\end{tabular}

Table shows the regression results for the energy markets' investor fear and panic taking into account total confirmed cases of COVID19. Standard errors and covariance are consistent with autocorrelation and heteroskedasticity of Newey-West. Estimation window from December 29, 2019, to May 30, 2020. Significant at *1\%, $* * 5 \%, * * * 10 \%$ level

fatality and the number of deaths during the pandemic outbreak has negatively impacted the energy stocks and futures market. Table 19 further reports the investors' sentiment during the infection period gauged in terms of implied volatility indexes. The estimates of COVID-19 cases across all volatility indexes appear positive and statistically significant (Baig et al. 2020). We can say that the rising cases of COVID19 infection affect the investors' sentiment, and market participants are worried about protecting their energy investments. The increased level of energy markets' volatility indicates a shortage of futures and options line in the energy market segment.

\section{Conclusion and policy implications}

The global energy sector has been solid hit by the pandemic and resulted in dwindling demand; collective with the provisional upsurge in supply has caused the highest energy market volatility. In this article, we presented the behavior of the energy market amid the COVID-19 pandemic outbreak. Our work considers three different asset classes of energy markets: energy stock indexes, crude oil futures, and ETFs. Further, we demonstrated the investors' fear and panic in the energy markets based on implied volatility indexes. The work also regards the disease outbreak news (DONs) in the form of WHOs announcement, Fed's FOMC statement, and GDP and unemployment report.

The increased cases of COVID-19 have disrupted the global supply chain and financial system. Lockdown and suspension of international travel have decreased fuel consumption and, consequently, lack of demand for crude oil. It has been observed that ProShares Short Oil and Gas and ProShares UltraShort Oil and Gas ETFs are found to be more defensive following the tail events. OVX is one of the most preferred readings of the investors' sentiment in the energy market. On 
average, reading stood $89.88 \%$ during the pandemic, with a maximum level of $325.15 \%$ and a minimum of $27.66 \%$.

The excess market returns, which appear favorable (DJUSEN, SPN, WTI, Brent, IYE, and DDG) and more than unity, indicate return sensitivity concerning systematic risk. However, the estimated beta (excess market returns) for the ETFs (DDG and DUG) was calculated adversely and statistically significantly. The essential findings are that DDG and DUG funds are less responsive to the market risk and can act as a defensive asset class for risk management. The empirical results indicate that the news about pandemic infections does not matter for the DDG and DUG funds. These funds represent a safe-haven for ETF investors. Moreover, EFTs such as DDG and DUG help the investor in risk aversion. The statistical outcome reveals that WHO-DONs matter for the energy market performance. Federal actions to combat the COVID-19 crisis fail to control the overreaction of the energy market performance. The significant positive slopes (OVX, VXXLE, OIV) indicate that investors' worries and fear were at an extreme level. In order to hedge energy stocks, investors have paid a higher premium for the put options. Further, Federal actions cannot reduce the likely impact of the pandemic crisis in the energy markets amid COVID-19. The news about COVID-19 fatality and the number of deaths during the pandemic outbreak has negatively impacted the energy stocks and futures market. The increased level of energy markets' volatility indicates a shortage of futures and options in the energy market segment.

The practical and policy implications are twofold: (1) to combat pandemic uncertainty administration, need to have a separate mechanism in which macroeconomic forecasting performed based on the health and infection statistics; (2) there is a scarce of the hedge funds in the energy market to protect energy holdings, so there is an urgent need for cost-effective risk management products (i.e., futures and options) to encompass the uncertain tail events. The present study demonstrates the energy market response amid the COVID-19 pandemic; other markets such as equity, FX, and commodities like gold, silver, and other precious metals may also exhibit extreme volatility. WHO's announcements and Federal support hold some implications for equity, FX, and commodities.

\section{Appendix A}

See Table 20 
Table 20 Important energy sector ETF Index

\begin{tabular}{ll}
\hline Index & Description \\
\hline iShares U.S. Energy ETF & $\begin{array}{r}\text { The iShares U.S. Energy ETF seeks to track the investment results of } \\
\text { an index composed of U.S. equities in the energy sector. 1. Exposure } \\
\text { Ticker: IYE }\end{array}$ \\
$\begin{aligned} \text { to U.S. companies that produce and distribute oil and gas 2. Targeted } \\
\text { access to domestic energy stocks 3. Use to express a sector view } \\
\text { https://www.ishares.com/us/products/239507/ishares-us-energy-etf }\end{aligned}$
\end{tabular}

ProShares Short Oil \& Gas ETF

Ticker: DDG

ProShares Ultra Oil \& Gas ETF

Ticker: DIG

ProShares UltraShort Oil \& Gas ETF

Ticker: DUG
ProShares Short Oil \& Gas seeks daily investment results, before fees and expenses, that correspond to the inverse $(-1 \mathrm{x})$ of the daily performance of the Dow Jones U.S. Oil \& GasSM Index

This short ProShares ETF seeks a return that is $-1 \times$ the return of its underlying benchmark (target) for a single day, as measured from one NAV calculation to the next. Due to the compounding of daily returns, holding periods of greater than one day can result in returns that are significantly different than the target return and ProShares' returns over periods other than one day will likely differ in amount and possibly direction from the target return for the same period. These effects may be more pronounced in funds with larger or inverse multiples and in funds with volatile benchmarks. Investors should monitor their holdings as frequently as daily. Investors should consult the prospectus for further details on the calculation of the returns and the risks associated with investing in this product

https://www.proshares.com/funds/ddg.html

ProShares Ultra Oil \& Gas seeks daily investment results, before fees and expenses, that correspond to two times $(2 \mathrm{x})$ the daily performance of the Dow Jones U.S. Oil \& GasSM Index

This leveraged ProShares ETF seeks a return that is $2 \times$ the return of its underlying benchmark (target) for a single day, as measured from one NAV calculation to the next. Due to the compounding of daily returns, holding periods of greater than one day can result in returns that are significantly different than the target return and ProShares' returns over periods other than one day will likely differ in amount and possibly direction from the target return for the same period. These effects may be more pronounced in funds with larger or inverse multiples and in funds with volatile benchmarks. Investors should monitor their holdings as frequently as daily. Investors should consult the prospectus for further details on the calculation of the returns and the risks associated with investing in this product

https://www.proshares.com/funds/dig.html

ProShares UltraShort Oil \& Gas seeks daily investment results, before fees and expenses, that correspond to two times the inverse $(-2 \mathrm{x})$ of the daily performance of the Dow Jones U.S. Oil \& GasSM Index

This short ProShares ETF seeks a return that is $-2 \times$ the return of its underlying benchmark (target) for a single day, as measured from one NAV calculation to the next. Due to the compounding of daily returns, holding periods of greater than one day can result in returns that are significantly different than the target return and ProShares' returns over periods other than one day will likely differ in amount and possibly direction from the target return for the same period. These effects may be more pronounced in funds with larger or inverse multiples and in funds with volatile benchmarks. Investors should monitor their holdings as frequently as daily. Investors should consult the prospectus for further details on the calculation of the returns and the risks associated with investing in this product

https://www.proshares.com/funds/dug.html 


\section{Appendix B}

See Table 21

\section{Appendix C}

See Table 22

\section{Appendix D}

See Table 23

Table 21 Important energy sector volatility index

\begin{tabular}{ll}
\hline Index & Description \\
\hline OVX: Cboe Crude Oil ETF Volatility Index & The Cboe Crude Oil ETF Volatility Index ("Oil \\
& VIX", Ticker-OVX) measures the market's \\
& expectation of 30- day volatility of crude oil \\
prices by applying the VIX® methodology to & United States Oil Fund, LP (Ticker-USO) \\
& options spanning a wide range of strike prices \\
VXXLE: Cboe Energy Sector ETF Volatility Index & $\begin{array}{l}\text { Cboe Options Exchange (Cboe) now applies its } \\
\text { proprietary Cboe Volatility Index® (VIX®) } \\
\text { methodology to create indices that reflect } \\
\text { expected volatility for options on select } \\
\text { exchange- traded funds (ETFs) } \\
\text { Cboe calculates and disseminates the Cboe Energy } \\
\text { Sector ETF Volatility Index (ticker VXXLE), } \\
\text { which reflects the implied volatility of the XLE } \\
\text { ETF } \\
\text { NYMEX Crude Oil (WTI) Volatility Index was } \\
\text { developed by the CBOE in a licensing agree- } \\
\text { ment with the CME Group, which is the parent } \\
\text { company of the NYMEX. This index is quoted } \\
\text { with the symbol OIV. The OIV index is based on } \\
\text { implied volatility of options that trade on crude } \\
\text { oil future contracts with the base symbol OL }\end{array}$ \\
&
\end{tabular}




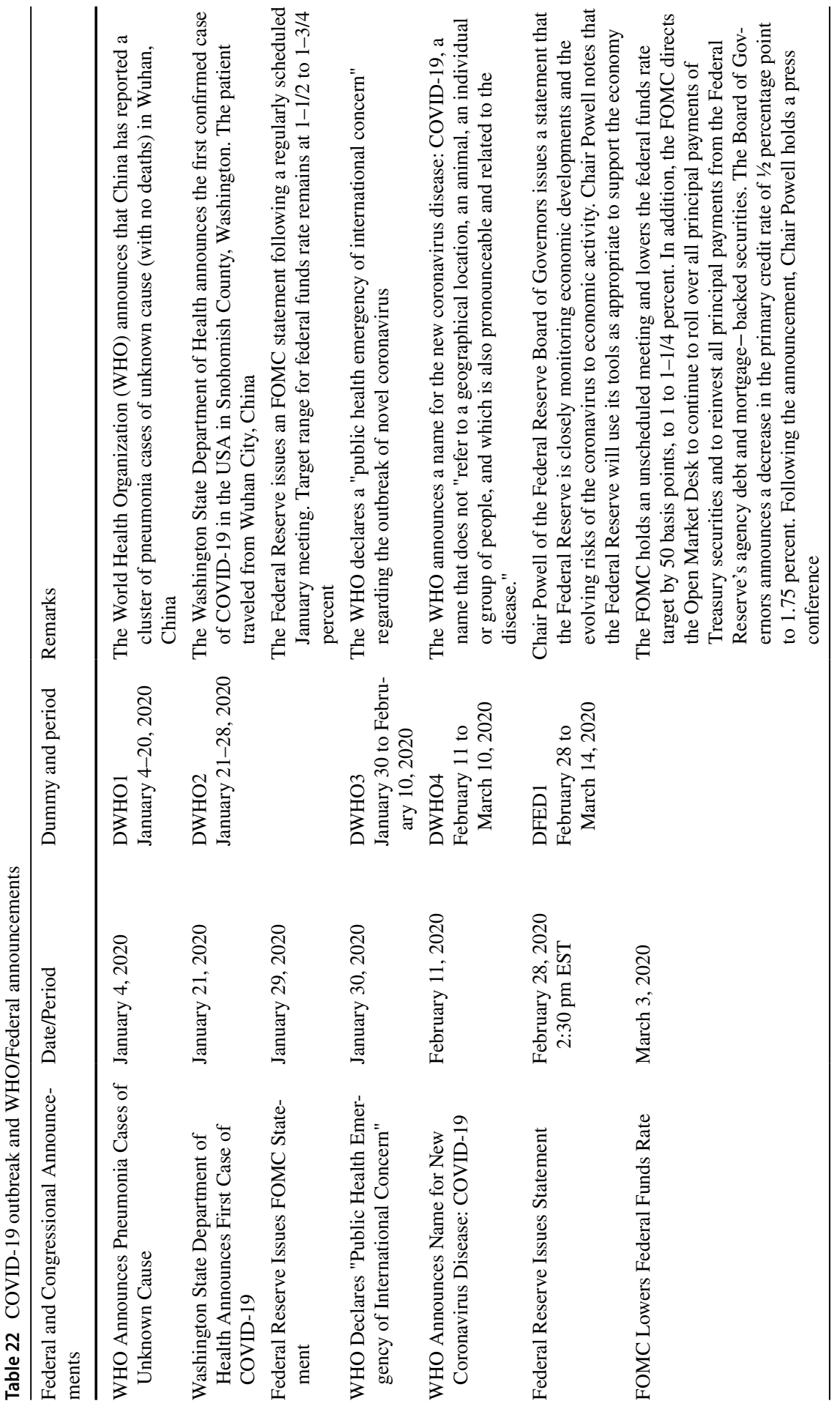




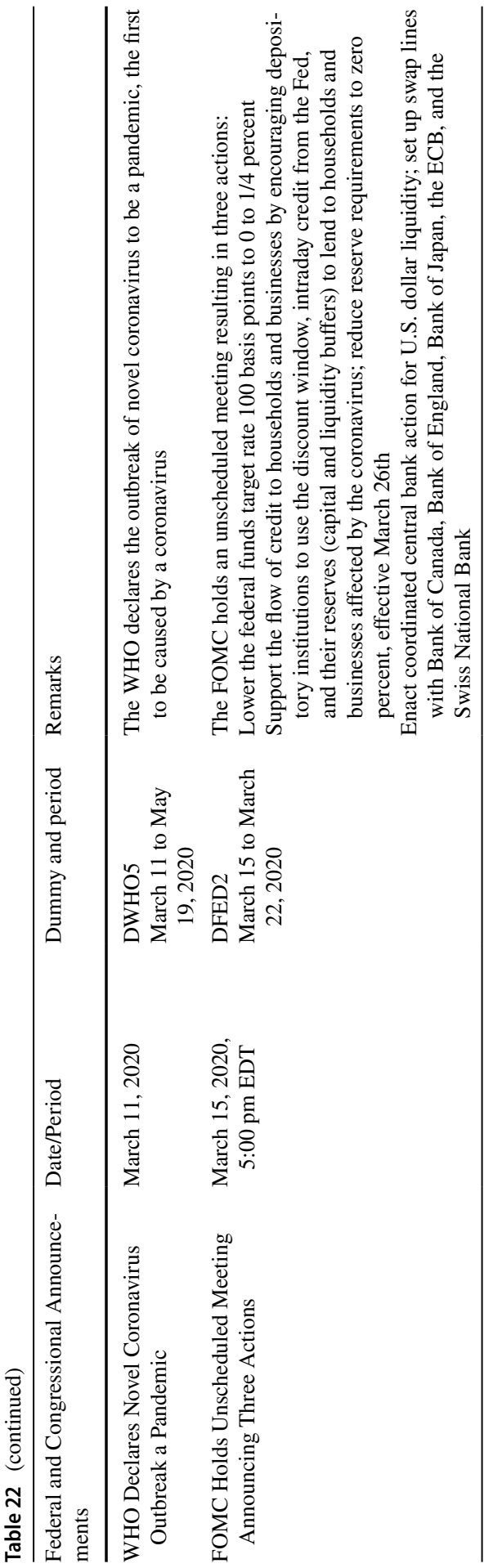




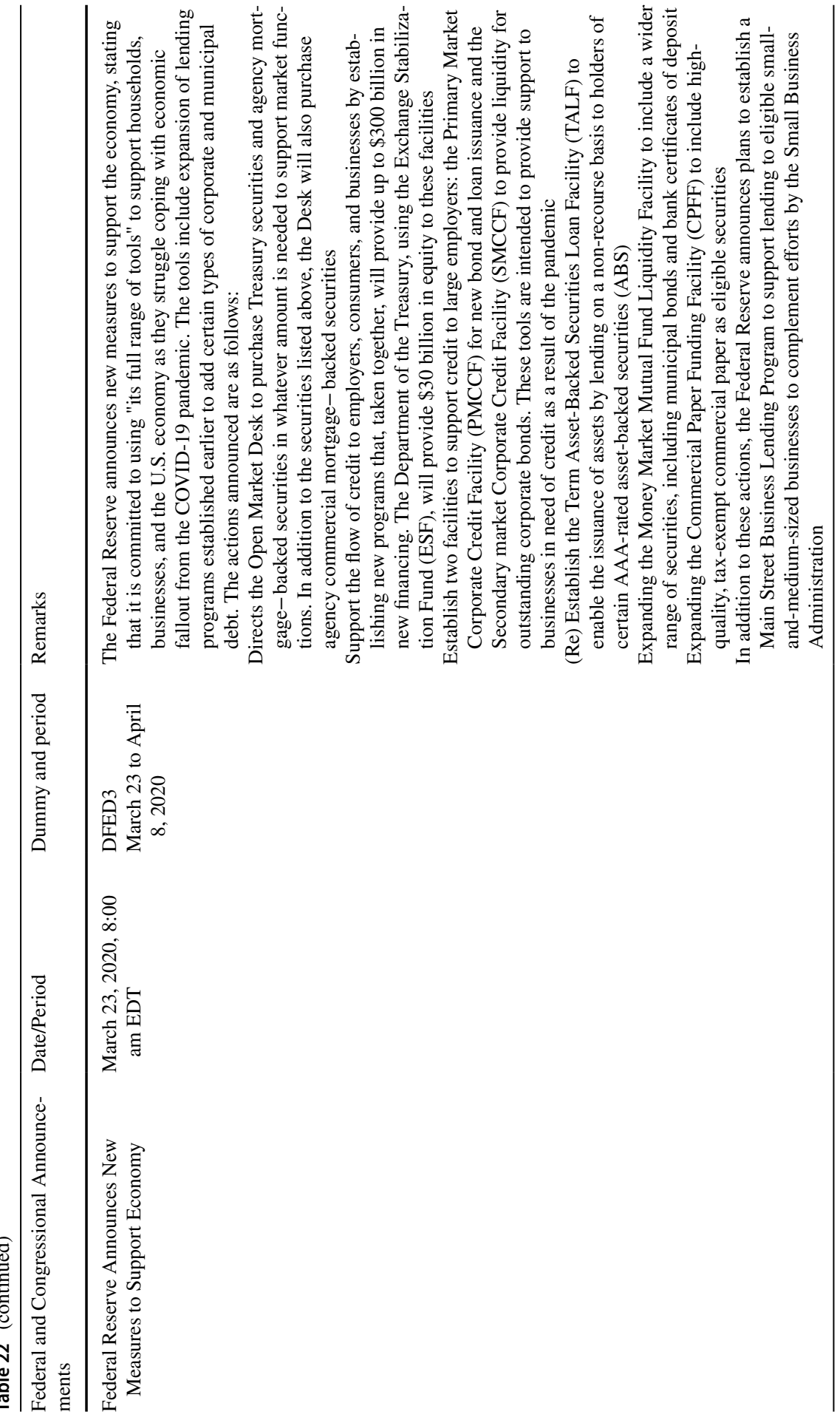




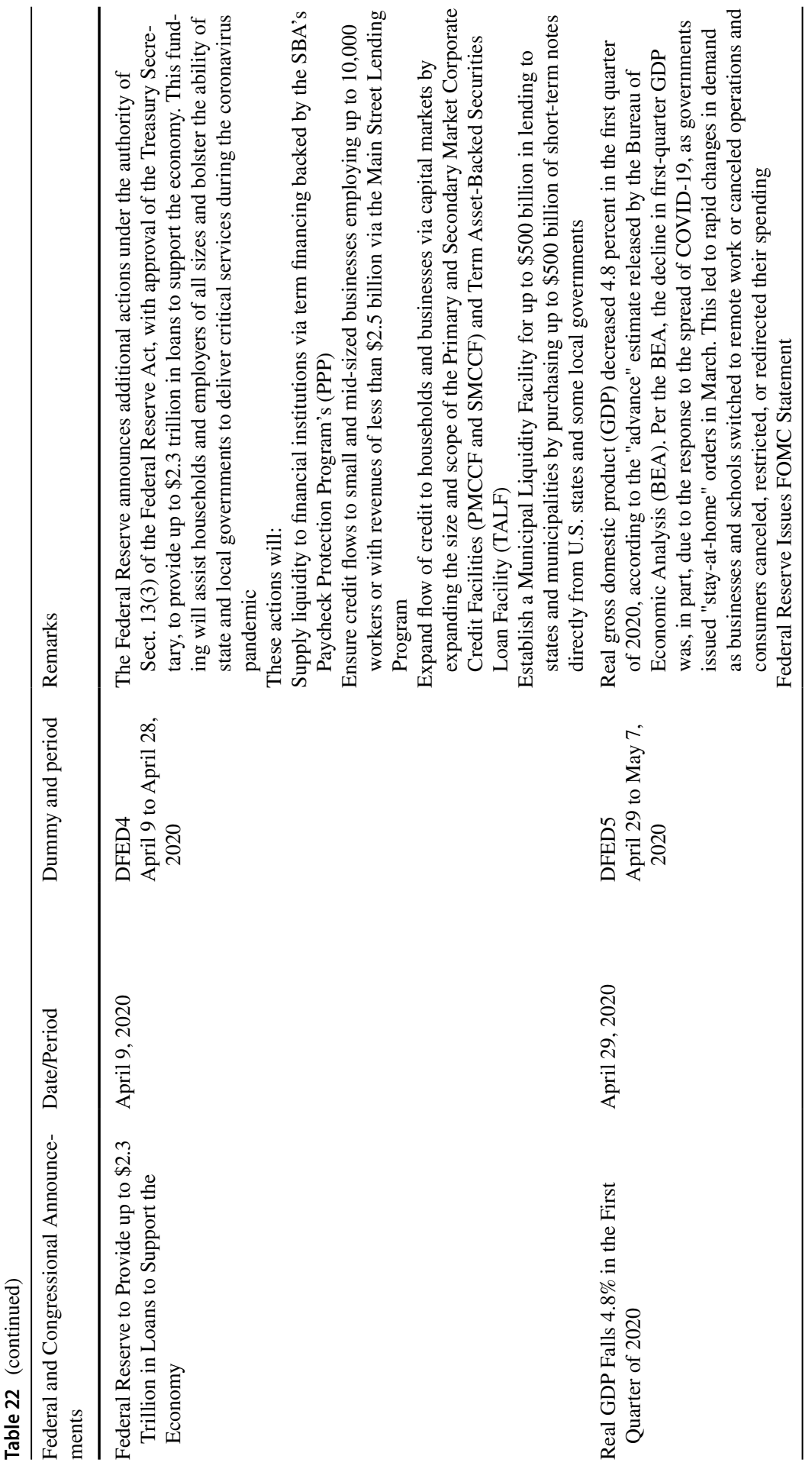




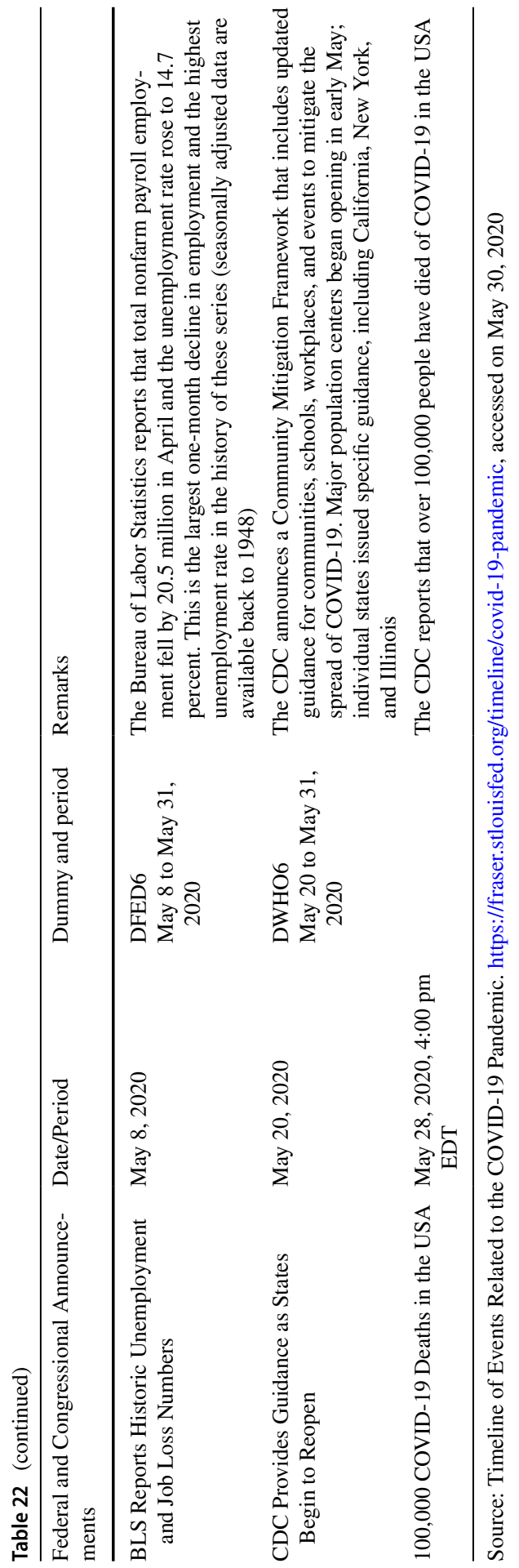




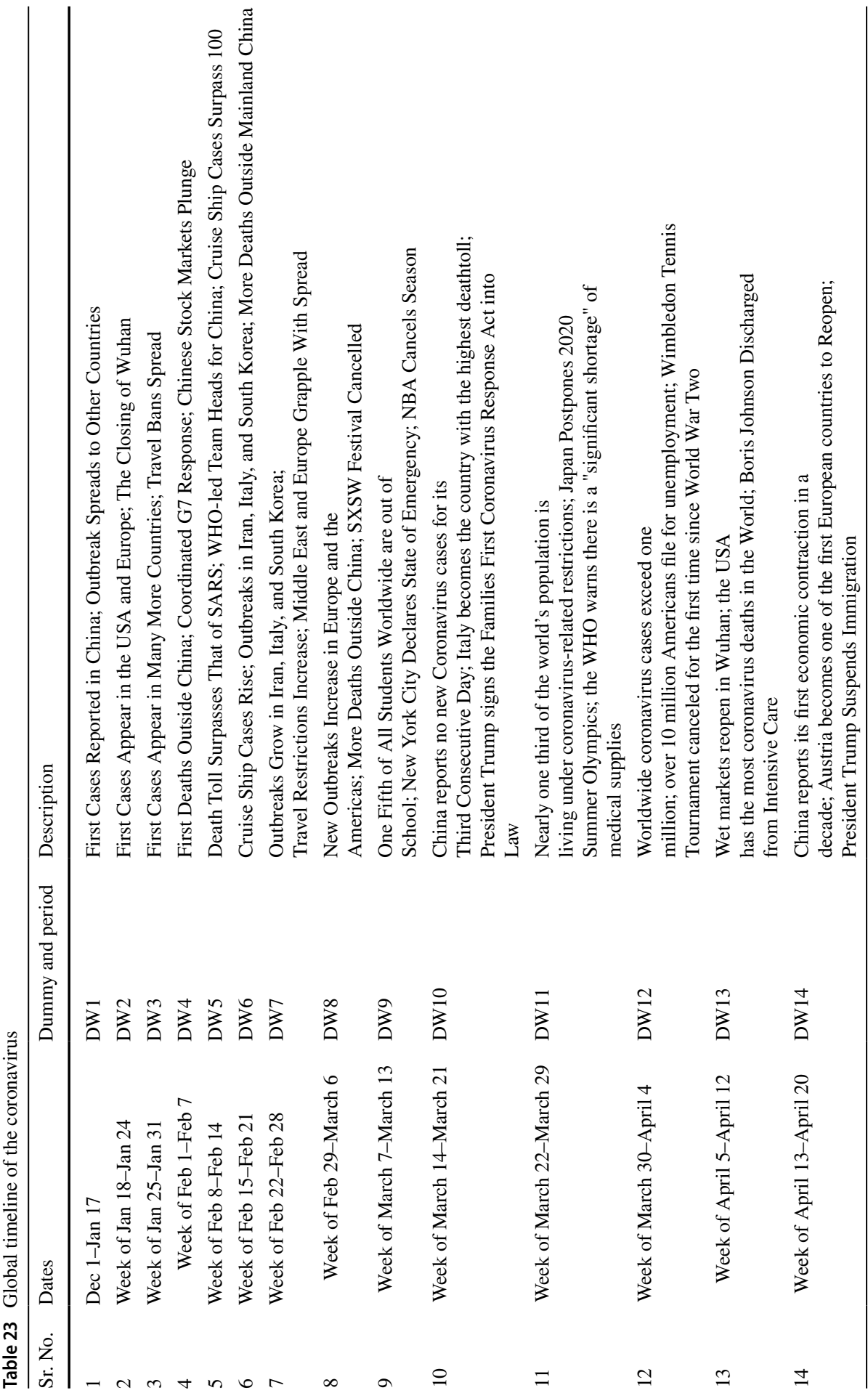




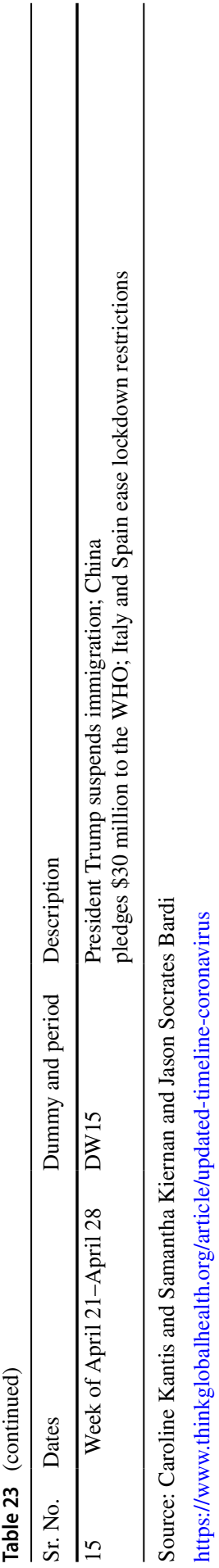

Springer 
Acknowledgements I want to thank editor-in-chief George Hondroyiannis for editorial comments and anonymous referees for their insightful observations and suggestions that have improved the work.

\section{References}

Akhtaruzzaman M, Boubaker S, Sensoy A (2020) Financial contagion during COVID-19 crisis. Financ Res Lett. https://doi.org/10.1016/j.frl.2020.101604

Al-Awadhi AM, Alsaifi K, Al-Awadhi A, Alhammadi S (2020) Death and contagious infectious diseases: Impact of the COVID-19 virus on stock market returns. J Behav Exp Finance 27:100326. https://doi. org/10.1016/j.jbef.2020.100326

AleaSoft. (2020) The consequences of the economic crisis of COVID 19 in the energy markets and their opportunities. https://aleasoft.com/: https://aleasoft.com/consequences-economic-crisi s-COVID-19-energy-markets-opportunities/. Accessed from 21 Apr 2020

Ali M, Alam N, Rizv SA (2020) Coronavirus (COVID-19)-An epidemic or pandemic for financial markets. J Behav Exp Financ. https://doi.org/10.1016/j.jbef.2020.100341

Andersen TG, Bollerslev T, Diebold FX, Ebens H (2001) The distribution of realized stock return volatility. J Financ Econ 61(1):43-76. https://doi.org/10.1016/S0304-405X(01)00055-1

Apergis E, Apergis N (2020) Can the Covid19 pandemic and oil prices drive the US Partisan Conflict Index. Energy Res Lett. https://doi.org/https://doi.org/10.46557/001c.13144.

Ashraf BN (2020) Stock markets' reaction to COVID-19: cases or fatalities? Res Int Bus Financ. https ://doi.org/10.1016/j.ribaf.2020.101249

Baig A, Butt HA, Haroon O, Rizvi SA (2020) Deaths, panic, lockdowns and US equity markets: The case of COVID-19 pandemic. SSRN. https://doi.org/10.2139/ssrn.3584947

Bakas D, Triantafyllou A (2020) Commodity price volatility and the economic uncertainty of pandemics. Econ Lett. https://doi.org/10.1016/j.econlet.2020.109283

Baker SR, Bloom N, Terry SJ (2020c) Does uncertainty reduce growth? Using disasters as natural experiments. NBER, http://people.bu.edu/stephent/files/BBT.pdf. Accessed from 2020

Baker SR, Bloom N, Davis SJ, Kost K, Sammon M, Viratyosin T (2020a). The unprecedented stock market reaction to COVID-19. White paper-Becker Friedman Institute for economics at UChicago, https://stockmarketjumps.com/files/COVIDMarketReaction.pdf. Accessed from 2020. pp 1-12

Baker S, Bloom N, Davis SJ, Terry SJ (2020) COVID-induced economic uncertainty. Natl Bur Econ Res. https://doi.org/10.3386/w26983

Balke NS, Brown SP (2018) Oil supply shocks and the US economy: an estimated DSGE model. Energy Policy 116:357-372. https://doi.org/10.1016/j.enpol.2018.02.027

Bansal T (2020) Behavioral finance and COVID-19: cognitive errors that determine the financial future. SSRN. https://doi.org/10.2139/ssrn.3595749

Benzid L, Chebb K (2020) The impact of COVID-19 on exchange rate volatility: evidence through GARCH model. SSRN. https://doi.org/10.2139/ssrn.3612141

Bocca, R. (2020, April 26). As coronavirus shocks the energy sector and economy, is now the time for a new energy order? https://www.weforum.org/: https://www.weforum.org/agenda/2020/04/energ y-oil-gas-electricity-sustainability-economy-covid19-coronavirus-pandemic-market-stability/. Accessed from 26 Apr 2020

Cen LL, Yang L (2013) Investor sentiment, disagreement, and the breadth-return relationship. Manage Sci 59(5):1076-1091. https://doi.org/10.1287/mnsc.1120.1633

Chen C-D, Chen C-C, Tang W-W, Huang B-Y (2009) The positive and negative impacts of the SARS outbreak: a case of the Taiwan industries. J Dev Areas, Accessed from https://www.jstor.org/stabl e/40376284. pp 281-293

Chen M-H, Jang SS, Kim., W. G. (2007) The impact of the SARS outbreak on Taiwanese hotel stock performance: an event-study approach. Int J Hosp Manag 26(1):200-212. https://doi.org/10.1016/j. ijhm.2005.11.004

Çıtak F, Bagci B, Şahin EE, Hoş S, Sakin İ (2020) Review of stock markets' reaction to COVID-19 news: fresh evidence from Quantile-on-Quantile regression approach. SSRN. https://doi.org/10.2139/ ssrn.3596931 
Cohen A (2020) Energy demand will never be the same after COVID-19, IEA report finds. https://www. forbes.com/: https://www.forbes.com/sites/arielcohen/2020/05/05/energy-demand-will-never-bethe-same-after-COVID-19-iea-report-finds/\#44826b524d22. Accessed from 5 May 2020

Corbet S, Hou Y, Hu Y, Lucey B, Oxley L (2020) Aye Corona! the contagion effects of being named Corona during the COVID-19 pandemic. Financ Res Lett. https://doi.org/10.1016/j.frl.2020.101591

Demir E, Bilgin MH, Karabulut G, Doke AC (2020) The relationship between cryptocurrencies and COVID-19 pandemic. SSRN. https://doi.org/10.2139/ssrn.3585147

Devpura N, Narayan PK (2020) Hourly oil price volatility: the role of COVID-19. Energy Res Lett 1(2):1-5. https://doi.org/10.46557/001c.13683

Donadelli M, Kizys R, Riedel M (2017) Dangerous infectious diseases: bad news for main street, good news for wall street? J Financ Mark 35:84-103. https://doi.org/10.1016/j.finmar.2016.12.003

Duong D, Huynh TL (2020) Tail dependence in emerging ASEAN-6 equity markets: empirical evidence from quantitative approaches. Financ Innov 6(1):1-26. https://doi.org/10.1186/s4085 4-019-0168-7

Ertuğrul HM, Güngör BO, Soytaş U (2020) The effect of the COVID-19 outbreak on the Turkish diesel. Energy Res Lett 1(3):1-4

Figlewski S (1997) Forecasting volatility Financial Markets, Institutions and Instruments. New York Univ Salomon Cent 6(1):1-88

Figueroa J, Counts T, Graves F, Mudge B, Pant S (2020) Impact of COVID-19 on the US energy industry. The Brattle Group Inc, Boston

Gil-Alana LA, Monge M (2020) Crude oil prices and COVID-19: persistence of the shock. Energy Res Lett. https://doi.org/10.46557/001c.13200

Glosten LR, Jagannathan R, Runkle DE (1993) On the relation between the expected value and the volatility of the nominal excess return on stocks. J Financ 48(5):1779-1801. https://doi. org/10.1111/j.1540-6261.1993.tb05128.x

Goodell JW, Huynh TL (2020) Did congress trade ahead? Considering the reaction of US industries to COVID-19. Financ Res Lett 36:101578. https://doi.org/10.1016/j.frl.2020.101578

Green TC, Figlewski S (1999) Market risk and model risk for a financial institution writing options. J Financ 54(4):1465-1499. https://doi.org/10.1111/0022-1082.00152

He P, Sun Y, Zhang Y, Li T (2020) COVID-19's impact on stock prices across different sectors-An event study based on the Chinese stock market. Emerg Mark Financ Trade 56(10):2198-2212. https ://doi.org/10.1080/1540496X.2020.1785865

Huynh TL, Shahbaz M, Nasir MA, Ullah S (2020) Financial modelling, risk management of energy instruments and the role of cryptocurrencies. Ann Oper Res. https://doi.org/10.1007/s1047 9-020-03680-y

Ichev R, Marinč M (2018) Stock prices and geographic proximity of information: evidence from the Ebola outbreak. Int Rev Financ Anal 56:153-166. https://doi.org/10.1016/j.irfa.2017.12.004

IEA (2020) COVID-19 exploring the impacts of the COVID-19 pandemic on global energy markets, energy. International Energy Agency, Paris, France

Ji Q, Zhang D, Zhao Y (2020) Searching for safe-haven assets during the COVID-19 pandemic. Int Rev Financ Anal. https://doi.org/10.1016/j.irfa.2020.101526

Kamstra MJ, Kramer LA, Levi MD (2003) Winter blues: a SAD stock market cycle. Am Econ Rev 93(1):324-343. https://doi.org/10.1257/000282803321455322

Kanno M (2020) Risk contagion of COVID-19 on Japanese stock market: a network approach. SSRN. https://doi.org/10.2139/ssrn.3599609

Kaplanski G, Levy H (2010) Exploitable predictable irrationality: the FIFA world cup effect on the US stock market. J Financ Quantitative Anal 45(2):535-553. https://doi.org/10.1017/S0022 109010000153

Kaplanski G, Levy H (2012) The holiday and yom kippur war sentiment effects: the Tel Aviv Stock Exchange (TASE). Quantitative Financ 12(8):1283-1298. https://doi.org/10.1080/14697 688.2010 .504225

Laxminarayan R, Malani A (2006) Economics of infectious diseases. Oxford Handb Health Econ. https://doi.org/10.1093/oxfordhb/9780199238828.013.0009

Lean HH, Nguyen DK (2014) Policy uncertainty and performance characteristics of sustainable investments across regions around the global financial crisis. Appl Financ Econ 24(21):13671373. https://doi.org/10.1080/09603107.2014.925063

Liu L, Wang E-Z, Lee C-C (2020) Impact of the COVID-19 pandemic on the crude oil and stock markets in the US: A time-varying analysis. Energy Res Lett. https://doi.org/10.46557/001c.13154 
Martín-Oliver A, Silaghi F (2020) Global financial crisis: mere dry run for COVID-19? SSRN. https:// doi.org/10.2139/ssrn.3599809

Narayan PK (2020) Oil price news and COVID-19-Is there any connection? Energy Res Lett. https:// doi.org/10.46557/001c. 13176

Narayan PK (2020) Has COVID-19 changed exchange rate resistance to shocks? Asian Econ Lett $1(1): 1-4$

Narayan PK (2020) Did Bubble Activity Intensify During COVID-19? Asian Econ Lett 1(2):1-5

Nguyen SP, Huynh., T. L. (2019) Portfolio optimization from a Copulas-GJRGARCH-EVT-CVAR model: empirical evidence from ASEAN stock indexes. Quantitative Financ Econ 3(3):562. https ://doi.org/10.3934/QFE.2019.3.562

Norouzi N, Rubens GZ, Choubanpishehzafar S, Enevoldsen P (2020) When pandemics impact economies and climate change: exploring the impacts of COVID-19 on oil and electricity demand in China. Energy Res Soc Sci 68:101654. https://doi.org/10.1016/j.erss.2020.101654

Ozili PK (2020) COVID-19 in Africa: socioeconomic impact, policy response and opportunities. Int J Sociol Soc Policy. https://doi.org/10.2139/ssrn.3574767

Papadamou SAF, Kenourgios D, Dimitriou, D (2020) Direct and indirect effects of COVID-19 pandemic on implied stock market volatility: evidence from panel data analysis. MPRA, https:// mpra.ub.uni-muenchen.de/id/eprint/100020. Accessed from 2020

Pendell DL, Cho C (2013) Stock market reactions to contagious animal disease outbreaks: an event study in Korean foot-and-mouth disease outbreaks. Agribusiness 29(4):455-468. https://doi. org/10.1002/agr.21346

Pham L, Huynh TL (2020) How does investor attention influence the green bond market? Financ Res Lett 35:101533. https://doi.org/10.1016/j.frl.2020.101533

Polemis M, Soursou S (2020) Assessing the Impact of the COVID-19 Pandemic on the Greek Energy Firms: An Event Study Analysis. Energy Res Lett 1(3):1-5. https://doi.org/10.46557/001c.17238

Qin M, Zhang Y-C, Su C-W (2020) The essential role of pandemics: a fresh insight into the oil market. Energy Res Lett 1(1):1-6

Ramkumar A, Hodari D (2020) Energy Crisis Intensifies as Oil Tumbles to 18-Year Low. Retrieved from WSJ: https://www.wsj.com/articles/u-s-oil-prices-drop-to-lowest-level-since-2002-11585570774

Rapier R (2020). Short term energy outlook shows impact of COVID-19 on energy sector. https:// www.forbes.com/: https://www.forbes.com/sites/rrapier/2020/05/17/short-term-energy-outlookshows-impact-of-COVID-19-on-energy-sector/\#16fdc2d045ed. Accessed from 17 May 2020

Salisu A, Adediran I (2020) Uncertainty due to infectious diseases and energy market volatility. Energy Res Lett. https://doi.org/10.46557/001c.14185

Samuel J, Rahman M, Ali GG, Samuel Y, Pelaez A (2020) Feeling like it is time to reopen now? COVID-19 new normal scenarios based on reopening sentiment analytics. SSRN. https://doi. org/10.2139/ssrn.3604802

Sands P, Turabi AE, Saynisch PA, Dzau VJ (2016) Assessment of economic vulnerability to infectious disease crises. Lancet 388(10058):2443-2448. https://doi.org/10.1016/S0140-6736(16)30594-3

Schell D, Wang M, Huynh TL (2020) This time is indeed different: a study on global market reactions to public health crisis. J Behav Exp Financ 27:100349. https://doi.org/10.1016/j.jbef.2020.100349

Seven U, Yilmaz F (2020) World equity markets and COVID-19: immediate response and recovery prospects. MPRA, https://mpra.ub.uni-muenchen.de/id/eprint/100987. Accessed from 2020

Smales LA (2020) Investor attention and global market returns during the COVID-19 crisis. SSRN. https ://doi.org/10.2139/ssrn.3623915

Suhrcke MS, McKee M, Tsolova S, Basu S, Abubakar I, Hunter P, Rechel B (2011) The impact of economic crises on communicable disease transmission and control: a systematic review of the evidence. PLoS ONE 6(6):e20724

Taylor JW (2004) Volatility forecasting with smooth transition exponential smoothing. Int J Forecast 20(2):273-286. https://doi.org/10.1016/j.ijforecast.2003.09.010

Taylor SJ (1987) Forecasting the volatility of currency exchange rates. Int J Forecast 3(1):159-170. https ://doi.org/10.1016/0169-2070(87)90085-9

Wallace J (2020) Coronavirus Threatens a Popular Crude Trade; The market's expectation of a fall in Chinese demand for oil is poised to erase profits for investors who purchase new, later-dated futures. Retrieved from WSJ: https://www.wsj.com/articles/coronavirus-threatens-a-popular-crude-trade $-11580906173$ 
Wang Y-H, Yang F-J, Chen L-J (2013) An investor's perspective on infectious diseases and their influence on market behavior. J Bus Econ Manag 14(sup1):S112-S127. https://doi.org/10.3846/16111 699.2012 .711360

Whaley RE (2000) The investor fear gauge. J Portf Manag 26(3):12-17

Yuen KS, Lee TM (2003) Could mood state affect risk-taking decisions? J Affect Disord 75(1):11-18. https://doi.org/10.1016/S0165-0327(02)00022-8

Zaremba A, Kizys R, Aharon DY, Demir., E. (2020) Infected markets: novel coronavirus, government interventions, and stock return volatility around the globe. Financ Res Lett. https://doi.org/10.1016/j. frl.2020.101597

Publisher's Note Springer Nature remains neutral with regard to jurisdictional claims in published maps and institutional affiliations. 